\title{
Analyse rétrospective des patients porteurs d'anticorps anti-TIF1gamma, anti-NXP2 et anti-SAE1/2 au CHU de Bordeaux de novembre 2014 à février 2017
}

\section{Retrospective analysis of anti-TIF1gamma, anti-NXP2 and anti-SAE1/2 antibodies carriers at Bordeaux University Hospital from November 2014 to February 2017}

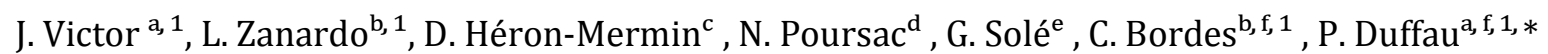

a Service de médecine interne, hôpital de Bordeaux, hôpital Saint-André, 1, rue Jean-Burguet, 33000 Bordeaux, France

b Laboratoire d'immunologie et immunogénétique, hôpital de Bordeaux, 33000 Bordeaux, France

${ }^{\text {c }}$ Service de dermatologie, hôpital de Bordeaux, 33000 Bordeaux, France

d Service de rhumatologie, hôpital de Bordeaux, 33000 Bordeaux, France

e Service de neurologie, hôpital de Bordeaux, 33000 Bordeaux, France

${ }^{\mathrm{f}}$ CNRS-UMR5164 immuno ConcEpT, université de Bordeaux, 33000 Bordeaux, France

${ }^{1}$ Ces auteurs ont contribué de manière identique à ce travail.

* Auteur correspondant

Adresse e-mail : pierre.duffau@chu-bordeaux.fr

Téléphone : 0556795728 


\section{Résumé}

Introduction: Les dermatomyosites sont des pathologies auto-immunes rares. La découverte de nouveaux anticorps spécifiques des dermatomyosites a permis de faire émerger des sous-groupes de patients, parmi eux, les anticorps anti-TIF1Y, les antiSAE1/2 et les anti-NXP2. Le développement récent de kits de dosage de routine pour la détection de ces auto-anticorps, basés sur la technique d'immunodot, est une avancée dans le diagnostic des dermatomyosites. Toutefois, le partage d'expérience sur les difficultés de l'interprétation des immunodots est indispensable. Nous rapportons ici le profil clinique des patients chez lesquels ces auto-anticorps ont été retrouvés entre 2014 et 2017 au CHU de Bordeaux, et discutons de la fréquence et des causes potentielles de positivité non associées à un contexte clinique de dermatomyosite.

Méthodes : Cette étude monocentrique et rétrospective a été menée de novembre 2014 à février 2017 au CHU de Bordeaux. Tous les patients porteurs d'anticorps anti-TIF1Y, anti-SAE1/2 et anti-NXP2, détectés par immunodot, ont été inclus.

Résultats : Cinquante-huit patients ont été inclus : 10 avaient une authentique dermatomyosite et 48 ont été considérés comme des faux positifs. Les 7 patients atteints de dermatomyosites à anti-TIF1Y étaient porteurs d'une néoplasie et, au terme du recueil, seule une patiente était en vie. Sur les 48 faux positifs, 30 patients étaient atteints d'une maladie auto-immune ou inflammatoire et 39 patients présentaient une dysimmunité significative. Aucun de ces patients n'a développé de dermatomyosite au cours du suivi.

Conclusion : Notre immunodot a permis le diagnostic de 10 nouvelles dermatomyosites. En revanche, le nombre important de faux positifs soulève le problème des performances des immunodots et incitent à un dialogue précoce avec les biologistes devant les difficultés d'interprétation potentiellement rencontrées.

Mots clés : Dermatomyosite, anti-TIF1Y, anti-SAE1/2, anti-NXP2, immunodot 


\section{$\underline{\text { Abstract }}$}

Introduction: Dermatomyositis are rare autoimmune diseases. The discovery of specific antibodies such as the anti-TIF1Y, anti-SAE1/2 and anti-NXP2 antibodies has been associated with specific clinical phenotypes. The recent development of standardized kits based on immunodot method is a progress in dermatomyositis diagnosis. Here we report the clinical characteristics of patients carrying these antibodies with or without clinical setting of dermatomyositis.

Methods: This single center french retrospective study was conducted from November 2014 to February 2017 at Bordeaux University Hospital. Patients carrying anti-TIF1X, anti-SAE1/2 and anti-NXP2 antibodies, detected by immunodot, were included.

Results: Among the 58 patients included only 10 were finally diagnosed with dermatomyositis. Some form of cancer was found in all anti-TIF1Y antibodies positive patients associated with dermatomyositis. Among the 48 anti-TIF1Y, anti-SAE1/2 and anti-NXP2 antibodies positive patients without clinical phenotype of dermatomyositis, 30 had autoimmune or inflammatory condition and 39 patients presented a significant biological autoimmunity. None of them developed dermatomyositis during the followup.

Conclusion: The immunodot kit allowed the diagnosis of 10 dermatomyositis. A high number of autoantibody positive patients without dermatomyositis raises the issue of the immunodot's performances in the context of biological autoimmunity.

Key words: Dermatomyositis, anti-TIF1Y, anti-SAE1/2, anti-NXP2, immunodot, 


\section{Introduction}

Les dermatomyosites (DM) sont des pathologies auto-immunes rares appartenant au groupe hétérogène des myopathies inflammatoires (MI). Leur incidence est estimée entre 1.2 et 17 nouveaux cas par million d'habitants/an [1].

Elles sont caractérisées par une atteinte musculaire correspondant habituellement à un déficit moteur d'installation progressive, proximal, bilatéral et symétrique parfois associé à des myalgies spontanées ou provoquées à la palpation. Les signes cutanés sont dominés par les papules et le signe de Gottron, le rash héliotrope, le signe du V et du châle, et le signe de la manucure.

Sur le plan paraclinique, on retrouve des CPK augmentées dans 75 à 85\% des cas [2] reflétant une activité de la maladie et une souffrance musculaire aigue. L'électromyogramme (EMG) permet d'éliminer une atteinte du système nerveux périphérique ou de la jonction neuromusculaire en retrouvant un syndrome myogène et de guider la biopsie musculaire. L'IRM musculaire est de plus en plus utilisée dans l'évaluation initiale et le suivi des patients. Elle permet d'évaluer l'activité de la maladie et de guider la biopsie musculaire qui reste le meilleur outil diagnostique dans les MI [3] mais sa réalisation n'est pas systématique dans les cas typiques [4]. Les anomalies histologiques principales des DM associent un dépôt de complément dans les capillaires musculaires, une atrophie périfasciculaire, un infarctus musculaire avec infiltrat inflammatoire péri-vasculaire riche en lymphocytes $B$, en macrophages et en cellules dendritiques plasmacytoïdes [5].

Sur le plan immunologique, la découverte progressive de nombreux autoanticorps spécifiques ou associés aux MI a permis de démembrer des sous-groupes de patients présentant des caractéristiques cliniques, histologiques et pronostiques communes. On distingue ainsi [6]: les DM (dont amyopathique et « sine dermatitis »), les myosites de chevauchement dont les syndromes des anti-synthétases, les myopathies nécrosantes à médiation immune et les myosites à inclusions.

On estime maintenant à près de $70 \%$ les DM «séropositives » [7]. Chaque anticorps est relié à un profil clinique et pronostique propre permettant de guider la prise en charge et le suivi des patients. Il s'agit des anticorps : anti-Mi2, anti-MDA5, anti- 
TIF1 $\gamma$, anti-SAE1/2 et anti-NXP2. Leur détection en routine est désormais possible grâce à des kits commerciaux basés sur la technique d'immunodot.

Les anticorps anti-TIF1Y ont été découverts en 2006 grâce à une technique d'immunoprécipitation [8]. Ils sont retrouvés dans 7 à 31\% des DM de l'adulte et sont généralement associés à la présence d'une néoplasie (précessive ou au cours du suivi) et une atteinte cutanée sévère [7]. La fréquence de cancers, en cas de DM à anti-TIF1Y, varie selon les études de $22 \%$ [9] à 100\% [10].

Les anticorps anti-SAE1/2 ont été identifiés en 2007 par Betteridge et al. [11]. Leur prévalence est variable au sein des DM de l'adulte, où ils sont retrouvés dans 6 à 8\% des DM chez les caucasiens mais dans 2\% des DM au Japon [7] . Selon les études, il semblerait que le profil clinique des patients atteints de dermatomyosite à anti-SAE1/2 inclue une fréquence plus importante des manifestations cutanées à type de rash héliotrope et de papules de Gottron. Les données concernant les signes généraux, l'atteinte musculaire, pulmonaire ou articulaire, et l'association aux cancers sont discordantes.

Les anticorps anti-NXP2 ont été découverts en 1997 par Oddis et al. [12], et leur présence a été observée initialement dans les cas de dermatomyosite juvénile sévère. La prévalence chez l'adulte varie de 1 à $17 \%$ des DM alors qu'elle est de 20 à $25 \%$ dans les DM juvéniles [7]. Là aussi les données sont discordantes concernant le profil clinique des patients adultes atteints de DM à anti-NXP2.

Devant la découverte récente de ces anticorps et l'inclusion en novembre 2014 (pour les anti-TIF18) et en novembre 2015 (pour les anti-SAE1/2 et anti-NXP2) de leur recherche au panel de notre kit d'immunodot, l'objectif de ce travail était de recenser les patients porteurs de ces anticorps, détectés par immunodot et d'en décrire les profils cliniques. Dans un premier temps nous nous sommes intéressés aux patients présentant une authentique DM. Nous avons analysé leur tableau clinique en fonction des autoanticorps retrouvés et leur association éventuelle à une néoplasie. Compte-tenu d'une proportion non négligeable de dot myosite positifs ou douteux non associés à un tableau de DM nous avons ensuite décrit les profils cliniques et immunologiques de ces patients. 


\section{Méthodes}

\section{Etude}

Il s'agit d'une étude monocentrique, descriptive et rétrospective menée de novembre 2014 à février 2017 au CHU de Bordeaux, portant sur l'ensemble des immunodots ayant mis en évidence la présence d'anticorps anti-TIF1Y, anti-SAE1/2 ou anti-NXP2.

\section{Méthode de recensement des « cas »}

L'immunodot incluant la détection des anti-TIF1Y est disponible au laboratoire d'immunologie du CHU de Bordeaux depuis novembre 20142014 (immunodot Alphadia commercialisé par la société INGEN). La recherche des anti-SAE1/2 et des anti-NXP2 est possible depuis novembre 2015. Il permet de rechercher simultanément la présence de ces auto-anticorps mais comprend aussi les auto-anticorps anti-J01, EJ, Mi2, PL12, PL7, MDA5, SRP, SSA52 kDa (TRIM21). Il est usuellement appelé « dot myosite ».

Nous avons sollicité le laboratoire d'immunologie afin d'obtenir la liste des sérums sur lesquels la présence des anti-TIF1Y était retrouvée, de novembre 2014 à février 2017. Nous avons fait de même pour les anti-SAE1/2 et anti-NXP2 de novembre 2015 à février 2017.

Pour chaque dot myosite étaient notés la date de la demande, le service demandeur et le résultat du dot myosite: positif ou douteux. L'interprétation de l'immunodot était réalisé de manière visuelle et également à l'aide d'un logiciel d'interprétation après scan des bandelettes et comparaison du signal de chaque spécificité avec celui du contrôle négatif de la bandelette (scanner BlueScan et logiciel DrDot). Etait considéré comme positif un résultat mettant en évidence un signal visible et quantifiable (supérieur à 10 unités arbitraires) après scan de la bandelette. Un signal visible et quantifiable (inférieur à 10), ou visible (de niveau supérieur ou égal à celui du contrôle négatif) bien que non quantifiable par le logiciel étaient considérés comme douteux.

Un contrôle du sérum de 4 patients porteurs d'anticorps anti-TIF1Y a été adressé au laboratoire d'immunologie de Rouen qui dispose d'une technique «maison » reposant sur la technologie Luminex/ALBIA (addressable laser bead immuno assay) pour déterminer le taux d'anticorps anti-TIF1gamma. La technique ALBIA mesure une intensité 
moyenne de fluorescence de billes couplées à la protéine TIF1gamma recombinante en cytométrie de flux. Cette intensité est proportionnelle au taux d'anticorps [13].

\section{Méthodes de recueil des données :}

Les données ont été recensées de façon rétrospective grâce au logiciel commun aux 3 sites du CHU de Bordeaux (DXCare®). Pour les dossiers venant des centres hospitaliers généraux, elles l'ont été soit par consultation des dossiers in situ soit après récupération des courriers et des différents examens complémentaires.

Pour chaque patient étaient recueillis l'âge au jour du dosage, le sexe, la présence de signes généraux (fièvre, altération de l'état général), le motif de demande du dot et le contexte clinique, les comorbidités significatives et les traitements en cours, les données de l'examen clinique (myalgies, déficit, dysphagie/troubles de déglutition, dyspnée, signes articulaires, signes cutanés dont syndrome de Raynaud), les données biologiques (CPK, CRP, Lymphocytes, bilan immunologique) et paracliniques (EMG, scanner thoracique, biopsie musculaire, IRM musculaire, explorations fonctionnelles respiratoires (EFR), électrocardiogramme (ECG), échographie cardiaque transthoracique (ETT)). La recherche de néoplasie sous-jacente, si elle était effectuée, était également relevée (TEP scanner, scanner thoraco-abomino-pelvien, endoscopies digestives, mammographie).

La prise en charge thérapeutique et l'évolution des patients étaient également recueillies, et ce, jusqu'en mai 2017, soit un recul minimum de 3 mois pour les derniers patients inclus.

Nous avons ensuite utilisé successivement plusieurs critères pour établir les «cas positifs », ceux de Peter et Bohan [14], ceux de Dalakas et al. [15] et ceux de l'ENMC [16]. Les cas ne remplissant pas les critères pour, au moins, un diagnostic probable étaient considérés comme des faux positifs. Nous avons choisi d'appliquer les critères de Peter et Bohan car ils sont encore largement utilisés, simples en pratique courante, malgré leur manque de spécificité. Dans les cas applicables, nous avons complété en utilisant ceux de Dalakas et ceux de l'ENMC car une publication de Linklater en 2013 leur trouve respectivement une sensibilité de $77 \%$ et $71 \%$ et une spécificité de $99 \%$ et $82 \%$ [17]. 


\section{$\underline{\text { Résultats }}$}

\section{Population}

Sur la période étudiée, le laboratoire a reçu 1901 demandes de dot myosite, dont 1130 de novembre 2015 à février 2017. La présence des anti-TIF1Y a été retrouvée sur 36 dot myosite (1.89\%) pour 30 patients ( 2 patients ont eu 2 prescriptions et 2 en ont eu 3). La présence des anti-SAE1/2 a été retrouvée sur 20 prélèvements (1.77\%) pour 18 patients et celle des anti-NXP2 sur 15 prélèvements (1.3\%) pour 12 patients.

$\mathrm{Au}$ sein des patients anti-NXP2, un patient de 14 ans présentant une DM depuis l'enfance a été exclu d'emblée de l'analyse.

Sur les 30 patients anti-TIF1Y, il y avait 17 femmes et 13 hommes, avec une moyenne d'âge globale de 60,7 ans, respectivement de 56,6 ans pour les femmes et 66,2 ans pour les hommes. Nous n'avons recensé aucun cas pédiatrique.

Sur les 18 patients anti-SAE1/2, il y avait 10 femmes et 8 hommes, avec une moyenne d'âge globale de 64,9 ans, respectivement de 61 ans pour les femmes et 69,8 ans pour les hommes.

Sur les 11 patients anti-NXP2, il y avait 6 femmes et 5 hommes, avec une moyenne d'âge globale de 50,7 ans, respectivement de 48,5 ans pour les femmes et 53,4 ans pour les hommes.

Les motifs de réalisation du dot myosite en fonction des anticorps sont présentés dans la figure 1. On retrouvait 12 demandes devant des tableaux cliniques compatibles avec une DM, 10 devant des myalgies (dont 6 avec CPK augmentées), 6 dots myosites lancés à l'initiative des biologistes, 5 dans le cadre de suivi de MI connue, 10 pneumopathies interstitielles diffuses (PID), 8 sclérodermies systémiques, 1 tableau de patient présentant une polyarthralgie inflammatoire. Les motifs n'étaient pas retrouvés chez 7 patients. Les dots réalisés à l'initiative du laboratoire l'ont été en raison d'une fluorescence cytoplasmique en immunofluorescence indirecte (IFI) sur cellules HEp-2, 
aspect caractéristique des anticorps anti-synthétases (anti-J01 en particulier), anti-SRP et anti-MDA5 [18].

\section{Dermatomyosites à anti-TIF1X}

En l'absence de biopsie musculaire pour 27 patients, les critères de Dalakas n'ont pas pu être appliqués. Un diagnostic de DM, au moins probable, selon les critères de Peter et Bohan et/ou de l'ENMC a été porté pour 7 patients, 2 femmes et 5 hommes. La moyenne d'âge était de 67,3 ans, respectivement de 58 ans pour les femmes et 71 ans pour les hommes. Les caractéristiques de ces patients sont détaillées dans le tableau 1.

Tous les patients présentaient un tableau cutané typique et une atteinte musculaire sévère comprenant un déficit musculaire coté au moins à 3/5 en proximal ( 6 patients), une dysphagie avec fausses routes (5 patients) et/ou une rhabdomyolyse avec des CPK > $10 \mathrm{~N}$ (6 patients). La médiane des CPK était de $5200 \mathrm{U} / \mathrm{L}$ avec des valeurs comprises entre 500 et 11200 U/L. Un seul patient présentait un syndrome de Raynaud.

Nous n'avons pas retrouvé d'atteinte articulaire, cardiaque ou parenchymateuse pulmonaire.

Tous les patients avaient des anticorps anti-noyaux (AAN) sur cellules Hep-2 à un titre significatif, d'au moins $1 / 320$. Une fluorescence mouchetée était retrouvée pour 5 patients, une fluorescence finement mouchetée pour un patient, les données de la fluorescence n'était pas disponibles pour un patient. L'interprétation du dot myosite était positive pour 6 patients et douteuse pour 1 (patient G). Le patient F était porteur d'anticorps anti-SSA.

En revanche tous les patients étaient porteurs d'une néoplasie, diagnostiquée avant le début de la DM pour 3 : un adénocarcinome pulmonaire, 1 carcinome de vessie et un probable cholangiocarcinome, et au décours de la prise en charge pour 4 : un carcinome de vessie (bilan initial de néoplasie), un carcinome hépatocellulaire (bilan initial de néoplasie), un cancer bronchique à petites cellules (bilan initial de néoplasie) et un lymphome $\mathrm{B}$ diffus à grandes cellules (bilan de néoplasie répété à 1 an du diagnostic de DM devant une corticodépendance avec rechutes multiples). Au terme du recueil, seule la patiente atteinte du lymphome B était en vie. 


\section{Dermatomyosites à anti-NXP2 et/ou anti-SAE1/2}

L'analyse des données des 11 patients anti-NXP2 et des 18 anti-SAE1/2 avec les critères de Bohan et Peter, de Dalakas et de l'ENMC a permis de retrouver 5 patients avec un diagnostic de MI. La présence simultanée d'anti-NXP2 et d'anti-SAE1/2 a été documentée chez 2 patients. Une patiente présentait une myosite nécrosante à anti-SRP et un patient une myosite de chevauchement à anti-Ku, ils ont été reclassés dans les faux positifs suite à un dot myosite ultérieur montrant une négativation des anti-NXP2 et/ou anti-SAE1/2 mais la persistance respective des anti-SRP et anti-Ku.

Au total, il est resté 3 authentiques DM : 1 avec une double positivité et 2 DM à antiSAE1/2 dont une amyopathique. Pour les 3 patients, l'interprétation du dot myosite était positive. Les caractéristiques de ces patients sont détaillées dans le tableau 1.

Le patient double positif présentait une PID. Aucun des patients ne présentait d'atteinte articulaire ou cardiaque. La recherche de néoplasie s'est également révélée négative.

\section{Faux positifs}

Les 48 patients ( 29 femmes et 19 hommes) restant ont donc été considérés comme des faux positifs (FP), 23 avec des anti-TIF1Y (15 femmes et 8 hommes), 10 avec des antiNXP2 ( 6 femmes et 4 hommes) et 15 avec des anti-SAE1/2 (8 femmes et 7 hommes). La moyenne d'âge était de 58,7 ans, respectivement 55,6 ans pour les femmes et 63,5 ans pour les hommes. L'interprétation du dot myosite en terme d'intensité des spots était douteuse pour 19 patients ( 8 anti-TIF18, 6 anti-NXP2 et 5 anti-SAE1/2) et positive pour 29 (15 anti-TIF1Y, 4 anti-NXP2 et 10 anti-SAE1/2).

Les motifs de réalisation du dot myosite pour les FP sont présentés dans la figure 2. On retrouvait 10 demandes devant des myalgies (dont 6 avec CPK augmentées), 6 dots lancés à l'initiative des biologistes, 5 suivis de MI connue, 10 PID, 8 sclérodermies systémiques, 1 tableau de polyarthralgie inflammatoire et 1 tableau évocateur de DM (éruption des zones photo-exposées). Les motifs n'étaient pas retrouvés chez 7 patients. 
Les diagnostics retenus concernant ces patients faux positifs ont été : dix sclérodermies systémiques (dont huit avec des anti-centromères), cinq lupus (deux lupus cutanéoarticulaires quiescents avec syndrome des anti-phospholipides secondaire, deux lupus cutanéo-articulaires en poussée et un lupus articulaire chez une patiente présentant une pneumopathie infectieuse dans un contexte de mucoviscidose), cinq tableaux de myalgies inexpliquées (dont deux avec une augmentation des CPK considérée comme essentielle), quatre fibroses pulmonaires idiopathiques, deux syndromes des antisynthétases à anti-J01, deux myosites de chevauchement à anti-Ku, une myopathie nécrosante à anti-SRP (positivité successive pour anti-NPX2 et anti-SAE au cours du traitement par IgIV), deux pseudo-polyarthrites rhizoméliques, deux pneumopathies d'hypersensibilité, un tableau d'arthromyalgies inflammatoires non étiqueté, une hémolyse retardée post-artésunate dans un contexte d'accès palustre grave, une pneumopathie médicamenteuse au méthotrexate chez une patiente avec un terrain dysimmunitaire (recto-colite hémorragique et polyarthrite, patient 13), une péricardite chronique constrictive, une poussée de vascularite cryoglobulinémique, une poussée de polyarthrite rhumatoïde séronégative, une maladie de Takayashu quiescente, une périartérite noueuse, une panniculite cutanée d'évolution spontanément favorable, un syndrome de Sjogrën avec atteinte pulmonaire, une sarcoïdose systémique, une connectivite inclassée avec atteinte pulmonaire, une polyneuropathie axonale sensitive chez une patiente porteuse d'anti-DNA et un dossier sans diagnostic en dehors de la dilatation des bronches pour laquelle la patiente était suivie.

Les diagnostics retenus en fonction des motifs de réalisation du dot myosite ainsi que les détails du bilan immunologique sont présentés dans les tableaux 2 et 3 (anticorps antiTIF18), le tableau 4 (anti-SAE1/2) et le tableau 5 (anticorps anti-NXP2).

La présence des anti-TIF1Y a déclenché une recherche de néoplasie sous-jacente pour 7 patients. Six patients ont bénéficié d'un scanner thoraco-abdomino-pelvien, 4 d'un TEP scanner et 3 d'endoscopies digestives. Une patiente a eu une mammographie et 1 patient un dosage du PSA. Au terme du recueil, aucun cancer n'était déclaré chez ces patients ni chez ceux n’ayant pas bénéficié du bilan de néoplasie.

Quarante-quatre patients avaient une fluorescence en IFI sur cellules HEp-2. Des AAN à un taux significatif, d'au moins 1/160, étaient retrouvés chez 32 patients. Sept patients 
présentaient une fluorescence cytoplasmique isolée. Cinq patients présentaient des AAN à un taux non significatif de 1/80. Quatre patients avaient une IFI négative.

Un contrôle du sérum de 4 patients porteurs d'anticorps anti-TIF1Y a été adressé au laboratoire d'immunologie de Rouen.. Ce contrôle était négatif pour 3 patients et faiblement positif pour un.

\section{Discussion}

Au cours de la période étudiée, le dot myosite a permis de faire le diagnostic de 7 DM à anti-TIF1Y, 2 DM à anti-SAE1/2 et 1 DM à anti-SAE1/2 et anti-NXP2. La conception de l'étude ne nous permet pas de calculer la prévalence de ces anticorps au sein des DM ou des MI.

Malgré notre faible effectif, les profils cliniques des patients semblent compatibles avec les données de la littérature.

Concernant les DM à anti-TIF1Y, la présentation cutanée est classique. L'atteinte musculaire semble plus sévère dans notre cohorte avec une rhabdomyolyse constante et souvent majeure (CPK $>10 \mathrm{~N}$ chez 6 patients et $>20 \mathrm{~N}$ chez 5 patients). L'absence de PID semble habituelle et est rapportée dans la plupart des études [8-10,19,20]. L'association au cancer est de 100\% dans notre cohorte de patients, ce qui peut s'expliquer par le nombre de patients de sexe masculin $(n=5)$ et/ou âgés de plus de 60 ans $(n=5)$. En effet Fujimoto et al. ont retrouvé en 2012 une fréquence de néoplasie de 86\% chez les patients atteints de DM à anti-TIF1Y de plus de 60 ans [21]. Récemment une métaanalyse identifie l'âge supérieur à 45 ans et le sexe masculin comme des facteurs prédictifs de néoplasie chez les patients atteints de polymyosite ou DM. La présence d'une dysphagie, d'une myopathie d'évolution rapide (sur moins de 4 semaines) et de CPK élevées sont également rapportées comme des facteurs de risque ce qui est le cas chez la totalité des patients [22].

Concernant les types de cancers associés aux DM à anti-TIF18, nous avons retrouvés 2 carcinomes de vessie, 1 adénocarcinome pulmonaire, 1 cancer bronchique à petites cellules, 1 probable cholangiocarcinome, 1 lymphome B diffus à grandes cellules et 1 carcinome hépatocellulaire. Dans la littérature on retrouve cette même variété sans qu'un type de néoplasie soit plus retrouvé qu'un autre. En revanche une méta-analyse récente retrouve une fréquence moindre de cancers de l'estomac, de la prostate, de 
l'endomètre, de lymphome, de maladie de Hodgkin et de mélanome dans les néoplasies associées aux DM [23].

En revanche, aucun patient FP pour les anti-TIF1X n'a présenté de cancer au cours du suivi. Il semblerait que la présence de ces anticorps ne soit associée à un risque de néoplasie qu'en cas de tableau clinique de DM. En effet, ils ne sont retrouvés que chez $3.1 \%$ des cancers solides, $3.3 \%$ des syndromes paranéoplasiques et $1.3 \%$ des patients sains, dans une étude récente [24]. La recherche de néoplasie ne semble pas nécessaire en cas de positivité des anti-TIF1Y en l'absence de diagnostic de DM.

Concernant les anti-SAE1/2, les 2 patientes présentaient des signes cutanés typiques de DM. L'absence d'atteinte musculaire, définissant la DM amyopathique, chez une des patientes est également une présentation classique avec les anti-SAE1/2 [11,29-32]. Mais l'évolution en quelques mois vers une atteinte musculaire avec ou sans dysphagie est attendue. Concernant cette patiente, le manque de recul par rapport au diagnostic (6 mois) peut expliquer l'absence d'atteinte musculaire. Cependant il existe d'authentique DM amyopathique à anti-SAE1/2 ne développant pas d'atteinte musculaire au cours du suivi [32]. L'atteinte pulmonaire du patient double positif pourrait être en rapport avec la présence des anti-SAE1/2 car celle-ci est rapportée dans plusieurs études, avec 64 à $100 \%$ des patients touchés $[11,30,31,33]$. Cependant, chez les 2 patientes avec une DM à anti-SAE1/2, aucune PID n'était rapportée. Aucun cancer n’a été retrouvé chez ces patients. En dehors d'une étude retrouvant une fréquence de néoplasie à $57 \%$ dans les DM à anti-SAE1/2 [33], les autres études la rapportaient entre 0 et 25\% [11,20,29-32] avec une fréquence moyenne de $15.8 \%$.

Sur le plan des DM à anti-NXP2, le phénotype du seul patient a été d'interprétation difficile en raison d'une double positivité avec des anti-SAE1/2. Le tableau cutané est classique d'une DM avec un signe du V et du châle et un signe de Gottron au niveau des épaules. En revanche, il ne présentait pas de calcinose, association décrite chez l'adulte et statistiquement significative chez Cerebelli et al. [25] et Rogers et al. [26]. Celle-ci est cependant absente chez Bodoki et al. [20] et Ichimura et al. [27]. L'atteinte musculaire est typique d'une DM mais sévère avec myalgies, dysphagie, CPK très augmentées et atteinte des muscles respiratoires responsables d'un trouble ventilatoire restrictif. Il 
existe une atteinte pulmonaire parenchymateuse avec une PID, cette atteinte n' a été relevée que de façon sporadique dans les DM à anti-NXP2 [20]. La recherche de néoplasie s'est révélée négative ce qui semble contradictoire avec la littérature. En effet cette association entre anti-NXP2 et cancer est bien rapportée [20,26,27] et surtout chez les patients de sexe masculin et âgés [28].

Une des limitations majeures de cette étude rétrospective est l'absence d'EMG, d'IRM musculaire et/ou de biopsie musculaire pour la plupart des patients, nous empêchant d'appliquer les critères de Dalakas et de l'ENMC pour porter les diagnostics positifs de DM. Malgré leur manque de spécificité les critères de Peter et Bohan associés à l'analyse des 59 tableaux cliniques et immunologiques inclus ont permis le diagnostic de 10 authentiques DM (un patient avec une double positivité). Les 48 autres patients ont été considérés comme des FP après analyse des données disponibles.

On peut alors s'interroger sur la fiabilité de notre dot myosite. En effet, il s'agit d'un outil récent mais dont les performances, dans le diagnostic des MI, ont été évaluées par plusieurs études. Ghirardello et al. en 2010, rapportaient pour le kit testé une spécificité supérieure à 95\% pour les anti-J01, PL12, PL7, PmSCL, Ku. Les rares cas de FP pour les anti-Mi2 étaient des patients principalement atteints de lupus érythémateux systémique [34] ce qui est le cas pour 5 patients. Cavazzana et al. en 2016 comparait un kit à l'immunoprécipitation (IP) et retrouvait un bon agrément pour les anti-TIF1Y, MDA5 et NXP2 ; un agrément moyen pour les anti-Mi2 et anti-EJ et une discordance importante pour les anti-J01. Les positivités multiples étaient fréquentes avec le dot (17\%) et absente avec l'IP [35]. Tampoia et al. en 2016 ont testé 2 kits (pour un total de 22 anticorps) et retrouvait une sensibilité tout anticorps confondu de $54.7 \%$ et une spécificité pour chaque anticorps entre 98 et $100 \%$ chez les patients atteints de MI. Les données des kits testés concernant le groupe contrôle, incluant 49 patients porteurs d'autres maladies auto-immunes et 20 patients sains n'étaient pas disponibles [36]. En revanche, une étude testant les performances d'un kit chez des patients sains et des patients atteints de MI retrouvait la présence d'anticorps spécifiques des myosites chez 9\% des patients sains [37]. 
$\mathrm{Au}$ sein des $\mathrm{FP}$, on remarque que 39 patients présentent une dysimmunité significative en IFI et que 30 patients sont atteints d'une maladie auto-immune ou inflammatoire (dix sclérodermies systémiques dont huit avec des anti-centromères, cinq lupus avec des anti-DNA, cinq MI, deux pseudo-polyarthrites rhizoméliques, une polyarthrite rhumatoïde séronégative, une vascularite cryoglobulinémique en poussée, une rectocolite hémorragique, une maladie de Takayashu, une péri-artérite noueuse, une sarcoïdose, un syndrome de Sjogrën et une connectivite inclassée). Cette constatation soulève la question des performances analytiques des immunodots. Cellesci peuvent être influencées par 2 facteurs principaux: la source antigénique utilisée (nature et qualité) et les interférences provenant du sérum étudié. Ainsi, les facteurs rhumatoïdes, les cryoglobulines, les immunoglobulines monoclonales ou les hypergammaglobulinémies polyclonales sont connues pour interférer dans les immunodosages [38]. D’autre part des réactivités croisées peuvent être générées lorsque l'antigène utilisé partage un ou plusieurs épitopes avec un autre anticorps présent dans le sérum du patient. Une dénaturation antigénique permettant la reconnaissance d'un épitope cryptique ou d'un néo-épitope pourrait également contribuer à l'apparition de ces réactivités non spécifiques.

Les motifs de réalisation du dot myosite n'ont pas été retrouvés chez 7 patients sur 59. Sur les 52 dossiers analysables, les motifs étaient : tableau évocateur de DM $(n=12)$, myalgies avec CPK augmentées ( $n=6)$, myalgies avec CPK normales $(n=4)$, pneumopathie interstitielle diffuse $(n=10)$, tableau de sclérodermie $(n=8)$, examen réalisé devant une fluorescence cytoplasmique sur IFI ( $n=6)$, suivi de MI $(n=5)$ et polyarthralgie $(n=1)$.

La réalisation du dot est raisonnable en cas de myalgies avec augmentation des CPK et de tableau évocateur de DM. Elle le semble aussi en cas de myalgies proximales sans CPK car une MI au stade précoce peut ne pas présenter de rhabdomyolyse, les CPK étant normales dans 15 à 25\% cas [2]. Par ailleurs, on sait aussi que les syndromes de chevauchement et en particulier les syndromes des anti-synthétases avec anticorps antiPL7 ou anti-PL12 peuvent avoir une présentation initiale pulmonaire isolée [39] ce qui explique les demandes en cas de PID. Dans les syndromes des anti-synthétases, l'atteinte articulaire peut également être au premier plan [39] ce qui explique la demande devant une polyarthralgie d'horaire inflammatoire d'autant plus que la patiente présentait un syndrome de Raynaud. Les demandes pour suivi de sclérodermie sont quant à elles plus discutables. En effet, les anticorps recherchés par le dot ne sont habituellement pas 
retrouvés dans les sclérodermies [18]. L'explication vient de la conception même du bon de demande d'immunologie où la case à cocher pour la réalisation du dot s'intitule «Anti-synthétases/Sclérodermie/Myosites » et date de l'époque où les anti-PmScL et anti-Ku étaient inclus dans le panel, ces anticorps étant associés aux myosites de chevauchement et notamment aux scléromyosites. Concernant la réalisation lancé par le laboratoire devant une fluorescence cytoplasmique sur l'IFI, elle s'explique par le fait que certains anticorps associés aux myosites ne sont pas associés à une fluorescence nucléaire mais à une fluorescence cytoplasmique, il s'agit des anti-synthétases (anti-J01, PL7 et PL12 en particulier), des anti-MDA5 et des anti-SRP [18]. Devant une fluorescence cytoplasmique évocatrice, il est légitime de poursuivre les recherches d'identification de ces auto-anticorps. Pour le suivi des MI, on peut imaginer que le but était de suivre le taux d'anticorps car il semble corrélé à l'activité de la maladie pour les anti-J01, anti-Mi2 et anti-TIF1Y et au taux de CPK pour les anti-SRP [40], mais notre dot ne permet qu'une analyse qualitative ou, au mieux, semi-quantitative avec l'aide du scanner qui mesure l'intensité des spots.

Le dot myosite reste cependant un outil majeur d'aide au diagnostic des MI et a permis le diagnostic de 10 nouvelles DM au cours de la période étudiée mais aussi le diagnostic d'autres MI associées aux autres anticorps détectés. Cependant on déplore un grand nombre de faux positifs.

Ces derniers ont, pour la plupart, la particularité d'avoir une maladie auto-immune ou inflammatoire et/ou un bilan immunologique perturbé ce qui pose la question de la validité des immunodots chez ce type de patients. Par ailleurs un contrôle plus strict de sa prescription pourrait être envisagé avec une fiche de renseignement à remplir, comme cela a été réalisé il y a quelques années dans notre laboratoire pour la recherche d'ANCA [41]. Une modification du bon de demande avec individualisation de la demande de recherche des anticorps des myosites inflammatoires est en cours. La meilleure connaissance des interférences analytiques observées permet aux laboratoires de fournir aux prescripteurs une interprétation biologique plus pertinente des résultats et d'aider les fabricants à l'amélioration continue des performances analytiques des coffrets réactifs commercialisés. Un dialogue entre cliniciens et biologistes demeure primordial. 


\section{Conclusion}

Les DM sont des pathologies rares et potentiellement graves. Notre dot myosite a permis d'identifier 10 nouveaux patients atteints de DM. Les tableaux cliniques des DM à antiTIF1Y sont relativement classiques mais l'atteinte cutanée est souvent sévère et une dysphagie est fréquente. En revanche l'atteinte pulmonaire semble rare. La fréquence de néoplasie sous-jacente est élevée ce qui doit nous inciter à une vigilance particulière chez ces patients qui ont un pronostic sombre à court terme. La récente découverte des anticorps anti-SAE1/2 et anti-NXP2 et leur faible prévalence imposent des études complémentaires à plus grand effectif afin de définir plus précisément les profils cliniques des patients, notamment en ce qui concerne l'atteinte pulmonaire et l'association au cancer. Les signes musculaires et cutanés semblent classiques avec toutefois un début souvent amyopathique en cas d'anti-SAE1/2. Les techniques de détection princeps de ces anticorps étant basées sur la radioimmunoprécipitation, non réalisable en routine, plusieurs kits ont été commercialisés. Leur sensibilité, spécificité et validité restent à déterminer devant un nombre important de patients porteurs de ces anticorps sans tableau de myosite. La proportion non négligeable de FP retrouvée avec notre immunodot nous incite à rester prudent devant des résultats d'analyse pouvant être perturbés par de nombreux facteurs, notamment chez des patients présentant une forte dysimmunité et/ou une maladie auto-immune ou inflammatoire ce qui est le cas dans notre étude. L'analyse des tableaux cliniques des patients et un dialogue précoce avec les biologistes demeurent indispensables.

\section{Déclaration de liens d'intérêts}

Les auteurs déclarent ne pas avoir de liens d'intérêts 


\section{Références}

[1] Iaccarino L, Ghirardello A, Bettio S, Zen M, Gatto M, Punzi L, et al. The clinical features, diagnosis and classification of dermatomyositis. J Autoimmun 2014;4849:122-7.

[2] P. Cherin P. Myosites. EMC - AKOS (Traité de Médecine) 2011:1-11 [Article 5-0290]

[3] Dalakas MC. Inflammatory muscle diseases. N Engl J Med 2015;372:1734-47.

[4] Haute Autorité de Santé. PNDS dermatomyosite de l'enfant et de l'adulte. https://www.has-sante.fr/portail/upload/docs/application/pdf/2016-09/pnds__dermatomyosite_de_lenfant_et_de_ladulte.pdf. Internet. [cité 20 sept 2017].

[5] Benveniste 0, Dubourg 0, Herson S. Nouvelles classifications et physiopathologie des myopathies inflammatoires. Rev Med Interne 2007;28:603-12.

[6] Meyer A, Lannes B, Goetz J, Echaniz-Laguna A, Lipsker D, Arnaud L, et al. Les nouvelles myopathies inflammatoires. Rev Rhum 2017;84:392-402.

[7] Fujimoto M, Watanabe R, Ishitsuka Y, Okiyama N. Recent advances in dermatomyositis-specific autoantibodies. Curr Opin Rheumatol 2016;28:636-44.

[8] Targoff IN, Mamyrova G, Trieu EP, Perurena O, Koneru B, O’Hanlon TP, et al. A novel autoantibody to a $155-\mathrm{kd}$ protein is associated with dermatomyositis. Arthritis Rheum 2006;54:3682-9.

[9] Fiorentino DF, Kuo K, Chung L, Zaba L, Li S, Casciola-Rosen L. Distinctive cutaneous and systemic features associated with antitranscriptional intermediary factor- $1 \gamma$ antibodies in adults with dermatomyositis. J Am Acad Dermatol 2015;72:449-55.

[10] Fujikawa K, Kawakami A, Kaji K, Fujimoto M, Kawashiri S, Iwamoto N, et al. Association of distinct clinical subsets with myositis-specific autoantibodies towards anti-155/140-kDa polypeptides, anti-140-kDa polypeptides, and antiaminoacyl tRNA synthetases in Japanese patients with dermatomyositis: a singlecentre, cross-sectional study. Scand J Rheumatol 2009;38:263-7.

[11] Betteridge Z, Gunawardena H, North J, Slinn J, McHugh N. Identification of a novel autoantibody directed against small ubiquitin-like modifier activating enzyme in dermatomyositis. Arthritis Rheum 2007;56:3132-7.

[12] Oddis CV et al, Fertig N, Goel A, Espada G, Confalone Gregorian M, MaldonadoCocco JA, Londino AV. Clinical and serological characterization of the anti-MJ antibody in childhood myositis. n.d.;Arthritis Rheum 1997, 40:S139. 
[13] Aussy A, Langlois V, Bach B, Marie I, Jouen F, Levesque H, et al. Dermatomyosites de l'adulte à anticorps anti-TIF1g : un auto-anticorps de classe. Rev Med Interne 2016;37:A100-1.

[14] Bohan A, Peter JB. Polymyositis and dermatomyositis (first of two parts). N Engl J Med 1975;292:344-7.

[15] Dalakas MC, Hohlfeld R. Polymyositis and dermatomyositis. Lancet Lond Engl 2003;362:971-82.

[16] Hoogendijk JE, Amato AA, Lecky BR, Choy EH, Lundberg IE, Rose MR, et al. 119th ENMC international workshop: trial design in adult idiopathic inflammatory myopathies, with the exception of inclusion body myositis, 10-12 October 2003, Naarden, The Netherlands. Neuromuscul Disord NMD 2004;14:337-45.

[17] Linklater H, Pipitone N, Rose MR, Norwood F, Campbell R, Salvarani C, et al. Classifying idiopathic inflammatory myopathies: comparing the performance of six existing criteria. Clin Exp Rheumatol 2013;31:767-9.

[18] Satoh M, Tanaka S, Ceribelli A, Calise SJ, Chan EKL. A Comprehensive Overview on Myositis-Specific Antibodies: New and Old Biomarkers in Idiopathic Inflammatory Myopathy. Clin Rev Allergy Immunol 2017;52:1-19.

[19] Hoshino K, Muro Y, Sugiura K, Tomita Y, Nakashima R, Mimori T. Anti-MDA5 and anti-TIF1-gamma antibodies have clinical significance for patients with dermatomyositis. Rheumatol Oxf Engl 2010;49:1726-33.

[20] Bodoki L, Nagy-Vincze M, Griger Z, Betteridge Z, Szöllősi L, Dankó K. Four dermatomyositis-specific autoantibodies-anti-TIF1 $\gamma$, anti-NXP2, anti-SAE and anti-MDA5-in adult and juvenile patients with idiopathic inflammatory myopathies in a Hungarian cohort. Autoimmun Rev 2014;13:1211-9.

[21] Fujimoto M, Hamaguchi Y, Kaji K, Matsushita T, Ichimura Y, Kodera M, et al. Myositis-specific anti-155/140 autoantibodies target transcription intermediary factor 1 family proteins. Arthritis Rheum 2012;64:513-22. [22] Lu X, Yang H, Shu $\mathrm{X}$, Chen F, Zhang Y, Zhang S, et al. Factors predicting malignancy in patients with polymyositis and dermatomyostis: a systematic review and meta-analysis. PloS One 2014;9:e94128.

[23] Yang Z, Lin F, Qin B, Liang Y, Zhong R. Polymyositis/dermatomyositis and malignancy risk: a metaanalysis study. J Rheumatol 2015;42:282-91.

[24] Venalis P, Selickaja S, Lundberg K, Rugiene R, Lundberg IE. Anti-TIF1-gamma antibodies are not associated with other paraneoplastic rheumatic syndromes than dermatomyositis. Arthritis Care Res 2017.

[25] Ceribelli A, Fredi M, Taraborelli M, Cavazzana I, Franceschini F, Quinzanini M, et al. Anti-MJ/NXP-2 autoantibody specificity in a cohort of adult Italian patients with polymyositis/dermatomyositis. Arthritis Res Ther 2012;14:R97. 
[26] Rogers A, Chung L, Li S, Casciola-Rosen L, Fiorentino DF. The cutaneous and systemic findings associated with nuclear matrix protein-2 antibodies in adult dermatomyositis patients. Arthritis Care Res 2017.

[27] Ichimura Y, Matsushita T, Hamaguchi Y, Kaji K, Hasegawa M, Tanino Y, et al. AntiNXP2 autoantibodies in adult patients with idiopathic inflammatory myopathies: possible association with malignancy. Ann Rheum Dis 2012;71:710-3.

[28] Fiorentino DF, Chung LS, Christopher-Stine L, Zaba L, Li S, Mammen AL, et al. Most patients with cancer-associated dermatomyositis have antibodies to nuclear matrix protein NXP-2 or transcription intermediary factor $1 \gamma$. Arthritis Rheum 2013;65:2954-62.

[29] Betteridge ZE, Gunawardena H, Chinoy H, North J, Ollier WER, Cooper RG, et al. Clinical and human leucocyte antigen class II haplotype associations of autoantibodies to small ubiquitin-like modifier enzyme, a dermatomyositis-specific autoantigen target, in UK Caucasian adult-onset myositis. Ann Rheum Dis 2009;68:1621-5.

[30] Fujimoto M, Matsushita T, Hamaguchi Y, Kaji K, Asano Y, Ogawa F, et al. Autoantibodies to small ubiquitin-like modifier activating enzymes in Japanese patients with dermatomyositis: comparison with a UK Caucasian cohort. Ann Rheum Dis 2013;72:151-3.

[31] Ge Y, Lu X, Shu X, Peng Q, Wang G. Clinical characteristics of anti-SAE antibodies in Chinese patients with dermatomyositis in comparison with different patient cohorts. Sci Rep 2017;7:188.

[32] Tarricone E, Ghirardello A, Rampudda M, Bassi N, Punzi L, Doria A. Anti-SAE antibodies in autoimmune myositis: identification by unlabelled protein immunoprecipitation in an Italian patient cohort. J Immunol Methods 2012;384:128-34.

[33] Muro Y, Sugiura K, Nara M, Sakamoto I, Suzuki N, Akiyama M. High incidence of cancer in anti-small ubiquitin-like modifier activating enzyme antibody-positive dermatomyositis. Rheumatol Oxf Engl 2015;54:1745-7.

[34] Ghirardello A, Rampudda M, Ekholm L, Bassi N, Tarricone E, Zampieri S, et al. Diagnostic performance and validation of autoantibody testing in myositis by a commercial line blot assay. Rheumatol Oxf Engl 2010;49:2370-4.

[35] Cavazzana I, Fredi M, Ceribelli A, Mordenti C, Ferrari F, Carabellese N, et al. Testing for myositis specific autoantibodies: Comparison between line blot and immunoprecipitation assays in 57 myositis sera. J Immunol Methods 2016;433:1-5.

[36] Tampoia M, Notarnicola A, Abbracciavento L, Fontana A, Giannini M, Louis Humbel $\mathrm{R}$, et al. A New Immunodot Assay for Multiplex Detection of Autoantibodies in a 
Cohort of Italian Patients With Idiopathic Inflammatory Myopathies. J Clin Lab Anal 2016;30:859-66.

[37] Bundell C, Rojana-Udomsart A, Mastaglia F, Hollingsworth P, McLean-Tooke A. Diagnostic performance of a commercial immunoblot assay for myositis antibody testing. Pathology (Phila) 2016;48:363-6.

[38] Chevailler A BC, Carrère F. Dépistage des anticorps dirigés contre les antigènes nucléaires solubles. Rev Fr Lab 2006;2006:59-70.

[39] Hervier B, Benveniste O. Phénotypes cliniques et pronostic du syndrome des antisynthétases. Rev Med Interne 2014;35:453-60.

[40] Aggarwal R, Oddis CV, Goudeau D, Koontz D, Qi Z, Reed AM, et al. Autoantibody levels in myositis patients correlate with clinical response during B cell depletion with rituximab. Rheumatol Oxf Engl 2016;55:991-9.

[41] Biscay P, Ralazamahaleo M, Lazaro E, Richez C, Seneschal J, Rigothier C, et al. [Évaluation de la pertinence des demandes d'anticorps anticytoplasme des polynucléaires neutrophiles : étude rétrospective menée au sein du centre hospitalier universitaire de Bordeaux]. Rev Med Interne 2017. 
Figure 1: Motif de réalisation du dot myosite

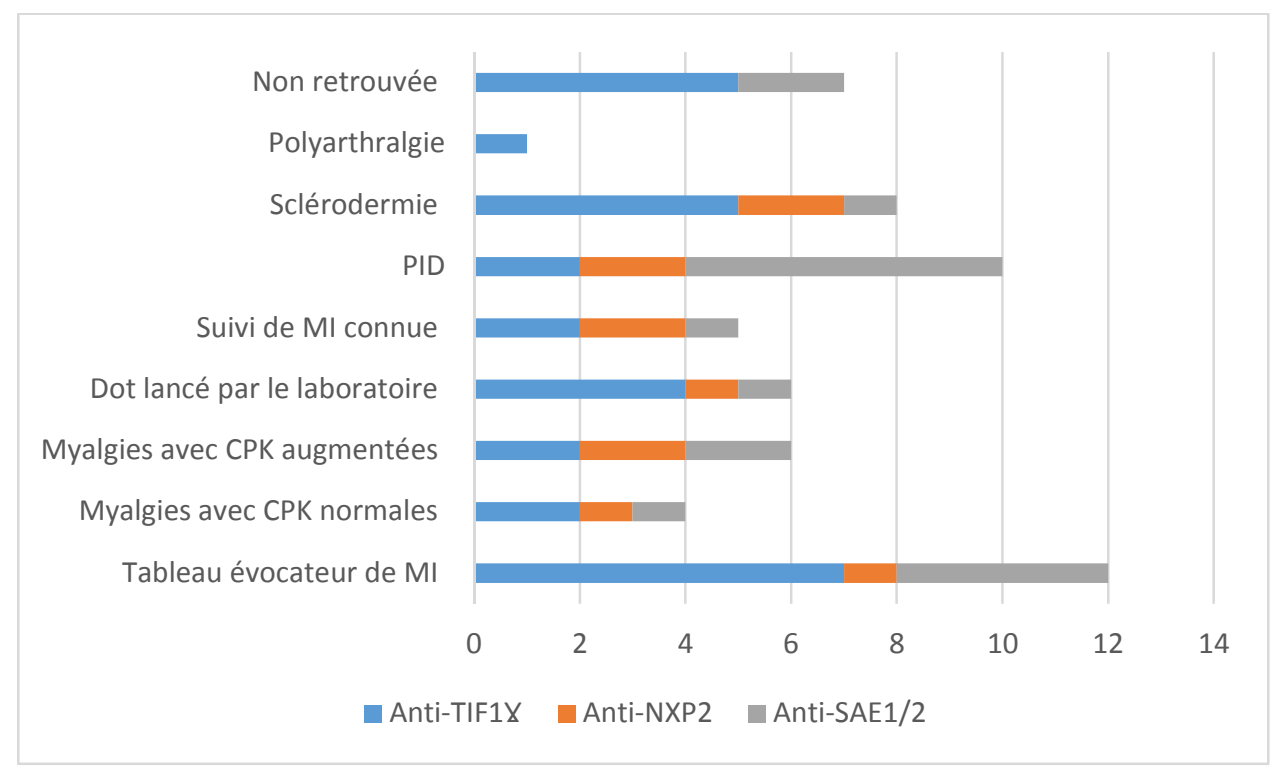


Figure 2: Motif de réalisation du dot myosite chez les faux-positifs

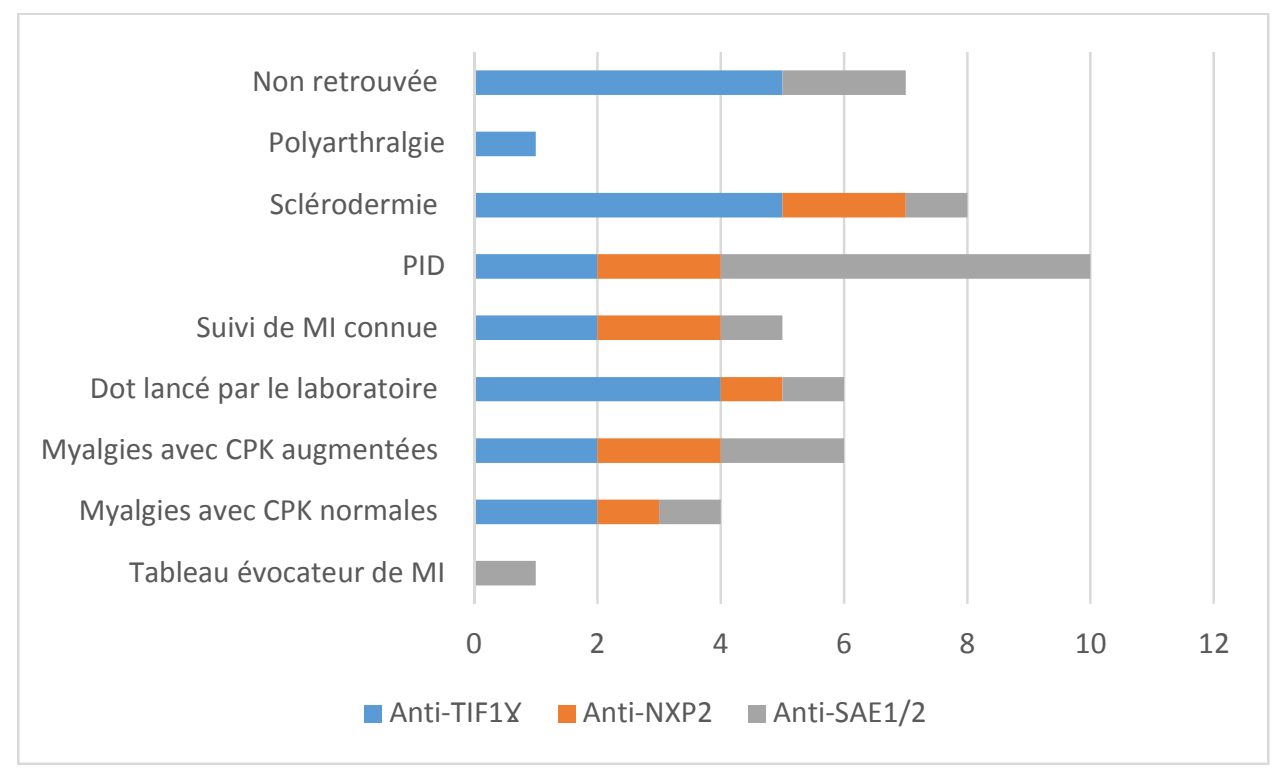


Tableau 1: Caractéristiques des DM

\begin{tabular}{|c|c|c|c|c|c|c|c|c|c|c|}
\hline & Patient A & Patient B & Patient C & Patient D & Patient E & Patient $\mathrm{F}$ & Patient $\mathbf{G}$ & Patient $\mathrm{H}$ & Patient I & Patient J \\
\hline Anticorps & Anti-TIF1X & Anti-TFIY & Anti-TIF1Y & Anti-TIF1X & Anti-TIF1X & Anti-TIF1Y & Anti-TIF1X & Anti-NXP2, AntiSAE1/2 & Anti-SAE1/2 & Anti-SAE1/2 \\
\hline Résultat & Positif & Positif & Positif & Positif & Positif & Positif & Douteux & Positif & Positif & Positif \\
\hline Age, Sexe & 54, Masculin & 72, Féminin & 44, Féminin & 69, Masculin & 71, Masculin & 80 , Masculin & 81 , Masculin & 62, Masculin & 76, Féminin & 60, Féminin \\
\hline Antécédents & $\begin{array}{l}\text { Cardiopathie } \\
\text { ischémique, Tabac, } \\
\text { Adénocarcinome } \\
\text { pulmonaire traité }\end{array}$ & $\begin{array}{l}\text { Alcoolisme chronique, } \\
\text { Psoriasis, Tabac, } \\
\text { Hépatite C active }\end{array}$ & Obésité & $\begin{array}{l}\text { Dyslipidémie, Goutte, } \\
\text { HBP, Tabac }\end{array}$ & $\begin{array}{l}\text { HBP, Tabac, Probable } \\
\text { cholangiocarcinome en } \\
\text { cours d'exploration }\end{array}$ & $\begin{array}{l}\text { HTA, Cancer de prostate en } \\
2014 \text { en rémission, Tabac }\end{array}$ & $\begin{array}{l}\text { HTA, IRC, Tabac, } \\
\text { Cancer de la vessie } \\
\text { suivi }\end{array}$ & 0 & $\begin{array}{l}\text { Morphée, PR } \\
\text { séropositive }\end{array}$ & Maladie de Basedow \\
\hline Début & 3 mois & 3 semaines & 3 mois & 1 mois & 1 mois & 1 mois & 1 mois & 1 mois & 1 an & 6 mois \\
\hline Signes généraux & Perte de poids & 0 & 0 & 0 & 0 & Perte de poids & $\begin{array}{l}\text { AEG franche et } \\
\text { rapide }\end{array}$ & Perte de $10 \mathrm{~kg}$ en 2 mois & Perte de 4kg en 6 mois & 0 \\
\hline Déficit & $\begin{array}{l}\text { Non chiffré, présent } \\
\text { Dysphagie, FR }\end{array}$ & Proximal $2 / 5$ & Proximal $3 / 5$ & $\begin{array}{l}\text { Proximal } 3 / 5 \\
\text { Dysphagie, FR }\end{array}$ & Dysphagie, FR & $\begin{array}{l}\text { Proximal } 3 / 5 \\
\text { Dysphagie, FR }\end{array}$ & $\begin{array}{l}\text { Proximal 2/5 } \\
\text { Dysphagie, FR }\end{array}$ & Proximal $4 / 5$ & Proximal $4 / 5$ & 0 \\
\hline Dyspnée & 0 & 0 & 0 & Stade II & 0 & Stade II & 0 & Stade III & Stade III & 0 \\
\hline Signes cutanés & $\begin{array}{l}\text { Raynaud } \\
\text { Rash héliotrope } \\
\text { Papules de Gottron } \\
\text { CEdème en pèlerine }\end{array}$ & $\begin{array}{l}\text { Rash héliotrope } \\
\text { Papules de Gottron } \\
\text { Signe du châle }\end{array}$ & $\begin{array}{l}\text { Rash héliotrope } \\
\text { Papules de Gottron }\end{array}$ & $\begin{array}{l}\text { Rash héliotrope } \\
\text { Papules de Gottron } \\
\text { Signe de la manucure } \\
\text { Livedo }\end{array}$ & $\begin{array}{l}\text { Rash héliotrope } \\
\text { Signe de la manucure }\end{array}$ & $\begin{array}{l}\text { EFdème en pèlerine } \\
\text { Signe du V et du châle } \\
\text { Sclérodactylie }\end{array}$ & $\begin{array}{l}\text { Rash héliotrope } \\
\text { Signe de la } \\
\text { manucure } \\
\text { Lésions ulcéro- } \\
\text { nécrotiques }\end{array}$ & $\begin{array}{l}\text { Signe du V } \\
\text { Signes du châle } \\
\text { Signe de Gottron (épaules) }\end{array}$ & $\begin{array}{l}\text { Morphée } \\
\text { Signe de Gottron } \\
\text { (genoux) } \\
\text { Erythème des paupières } \\
\text { Raynaud }\end{array}$ & $\begin{array}{l}\text { Papules de Gottron } \\
\text { Signe de la manucure } \\
\text { Hyperkératose peri- } \\
\text { unguéale }\end{array}$ \\
\hline CPK & $3.5 \mathrm{~N}$ & $>50 \mathrm{~N}$ & $30 \mathrm{~N}$ & $>50 \mathrm{~N}$ & $20 \mathrm{~N}$ & $10 \mathrm{~N}$ & $38 \mathrm{~N}$ & $20 \mathrm{~N}$ & $2 \mathrm{~N}$ & 0 \\
\hline $\begin{array}{l}\text { Bilan } \\
\text { immunologique }\end{array}$ & AAN $1 / 320$ & $\begin{array}{l}\text { AAN 1/1280, } \\
\text { Fluo mouchetée, } \\
\text { Cryoglobuline lla } \\
\text { Coombs + IgG }\end{array}$ & $\begin{array}{l}\text { AAN } 1 / 640, \\
\text { Fluo mouchetée }\end{array}$ & $\begin{array}{l}\text { AAN } 1 / 1280, \\
\text { Fluo finement } \\
\text { mouchetée, } \\
\text { Anti-TPO }\end{array}$ & $\begin{array}{l}\text { AAN } 1 / 2560, \\
\text { Fluo mouchetée, } \\
\text { Anti-TG, } \\
\text { Coombs + IgG }\end{array}$ & $\begin{array}{l}\text { AAN } 1 / 1280, \\
\text { Fluo mouchetée, } \\
\text { Anti SSA }\end{array}$ & $\begin{array}{l}\text { AAN } 1 / 320 \\
\text { Fluo mouchetée }\end{array}$ & $\begin{array}{l}\text { AAN } 1 / 1280 \\
\text { Fluo mouchetée }\end{array}$ & $\begin{array}{l}\text { AAN } 1 / 1280, \\
\text { Fluo finement } \\
\text { mouchetée, Fluo } \\
\text { cytoplasmique } 1 / 320\end{array}$ & $\begin{array}{l}\text { AAN } 1 / 640 \\
\text { Fluo finement } \\
\text { mouchetée }\end{array}$ \\
\hline EMG & Syndrome myogène & & Normal & -1 & & Syndrome myogène & & - & $\begin{array}{l}\text { Multinévrite } \\
\text { Syndrome myogène }\end{array}$ & Normal \\
\hline $\begin{array}{l}\text { Biopsie } \\
\text { musculaire }\end{array}$ & - & - & - & En faveur d'une DM & - & $\begin{array}{l}\text { En faveur d'une MI sans } \\
\text { aspect caractéristique de } \\
\text { DM }\end{array}$ & - & $\begin{array}{l}\text { En faveur d'une MI, Pas } \\
\text { d'infiltrat inflammatoire }\end{array}$ & $\begin{array}{l}\text { En faveur d'une MI, Pas } \\
\text { d'infiltrat inflammatoire }\end{array}$ & - \\
\hline EFR & & & & $\begin{array}{l}\text { Pas de TVR, DLCO N, } \\
\text { hypoxémie modérée }\end{array}$ & Normal & $\begin{array}{l}\text { Pas de TVR ni TVO } \\
\text { PEM diminuée }\end{array}$ & & $\begin{array}{l}\text { TVR, Atteinte des muscles } \\
\text { respiratoires }\end{array}$ & TVR & - \\
\hline Cancer & $\begin{array}{l}\text { Adénocarcinome } \\
\text { bronchique connu en } \\
\text { cours de traitement }\end{array}$ & $\begin{array}{l}\text { Diagnostic de carcinome } \\
\text { hépato-cellulaire au } \\
\text { cours de la PEC }\end{array}$ & $\begin{array}{l}\text { Diagnostic de LBDGC à } 1 \\
\text { an du diagnostic dans un } \\
\text { contexte de } \\
\text { corticodépendance }\end{array}$ & $\begin{array}{l}\text { Diagnostic de carcinome } \\
\text { de vessie infiltrant au } \\
\text { cours de la PEC }\end{array}$ & $\begin{array}{l}\text { Probable cholangio- } \\
\text { carcinome }\end{array}$ & $\begin{array}{l}\text { Diagnostic de CBPC au } \\
\text { cours de la PEC }\end{array}$ & $\begin{array}{l}\text { Récidive de cancer } \\
\text { de vessie }\end{array}$ & 0 & 0 & 0 \\
\hline Traitement & $\begin{array}{l}\text { CS, IgIV } \\
\text { Cisplatine, Taxotere }\end{array}$ & CS, IgIV & $\begin{array}{l}\text { CS, IgIV, MTX } \\
\text { RCHOP }\end{array}$ & $\begin{array}{l}\text { CS, IIIV, MTX } \\
\text { RTUV, indication à BCG } \\
\text { thérapie }\end{array}$ & $\begin{array}{l}\text { CS, IIIV } \\
\text { Gemcitabine }\end{array}$ & $\begin{array}{l}\text { CS, IIVI, AZA } \\
\text { Carboplatine, VP16 }\end{array}$ & $\mathrm{CS}, \mathrm{IgIV}$ & Bolus CS, IIIV, AZA & $\mathrm{CS}, \mathrm{IgIV}, \mathrm{MMF}$ & MTX \\
\hline Evolution & Décès à 18 mois & Décès à 1 mois & $\begin{array}{l}\text { En vie à } 24 \text { mois du } \\
\text { diagnostic }\end{array}$ & Décès à 8 mois & Décès à 5 mois & Décès à 1 an & Décès à 2 mois & $\begin{array}{l}\text { Rechute précoce, } \\
\text { intensification par } \\
\text { Endoxan puis Rituximab }\end{array}$ & $\begin{array}{l}\text { Rémission, espacement } \\
\text { progressif des IgIV }\end{array}$ & Rémission \\
\hline
\end{tabular}

AAN : anticorps anti-noyaux, AEG : altération de l'état général, AZA : Azathioprine, CBPC : cancer bronchique à petites cellules, CS : Corticostéroìdes, DLCO : capacité de diffusion du CO, Fluo : fluorescence, FR : fausses routes, HBP : hypertrophie bénigne de prostate, HTA : Hypertension

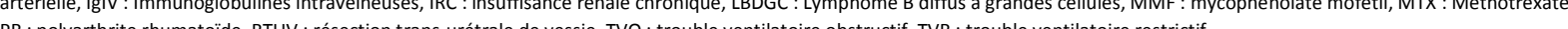
0 : signe clinique absent, - : examen non réalisé, $\mathrm{N}$ : normal 
Tableau 2: Diagnostics retenus chez les faux-positifs pour anti-TIF1Y en fonction des motifs de réalisation du dot myosite (patient 1 à 12)

\begin{tabular}{|c|c|c|c|c|c|c|c|c|c|}
\hline & Age, sexe & $\begin{array}{l}\text { Motif de } \\
\text { réalisation }\end{array}$ & Signes cutanés & $\begin{array}{l}\text { Signes } \\
\text { musculaires } \\
\text { CPK }\end{array}$ & $\begin{array}{l}\text { Examens réalisés } \\
\text { (EMG/IRM) }\end{array}$ & $\begin{array}{l}\text { Biopsie } \\
\text { musculaire }\end{array}$ & IFI sur HEp-2 & $\begin{array}{l}\text { Bilan } \\
\text { immunologique }\end{array}$ & $\begin{array}{l}\text { Diagnostics } \\
\text { retenus }\end{array}$ \\
\hline Patient 1 & $\begin{array}{l}\text { 54, M } \\
\text { Anti-TIF1X } \\
\text { positifs }\end{array}$ & $\begin{array}{l}\text { Dot myosite } \\
\text { lancé par le } \\
\text { laboratoire }\end{array}$ & 0 & $\begin{array}{l}\text { Myalgies diffuses } \\
\text { CPK N }\end{array}$ & - & - & $\begin{array}{l}\text { AAN } 1 / 360, \\
\text { Fluo mouchetée } \\
\text { Fluo cytoplasmique à } \\
1 / 1000\end{array}$ & $\begin{array}{l}\text { Anti- PL12, Ku, } \\
\text { PmScl, EJ } \\
\text { Cryoglobuline II b } \\
105, \\
\text { FR > } 200\end{array}$ & $\begin{array}{l}\text { Hémolyse retardée } \\
\text { post ARTESUNATE }\end{array}$ \\
\hline Patient 2 & $\begin{array}{l}88, \mathrm{M} \\
\text { Anti-TIF1Y } \\
\text { positifs }\end{array}$ & $\begin{array}{l}\text { Pneumopathie } \\
\text { interstitielle } \\
\text { diffuse }\end{array}$ & 0 & $\begin{array}{l}0 \\
\text { CPK } 1.5 \mathrm{~N}\end{array}$ & - & - & Fluo cytoplasmique & & $\begin{array}{l}\text { Fibrose pulmonaire } \\
\text { idiopathique }\end{array}$ \\
\hline Patient 3 & $\begin{array}{l}42, \mathrm{M} \\
\text { Anti-TIF1X } \\
\text { positifs }\end{array}$ & Non retrouvée & 0 & $\begin{array}{l}0 \\
\text { CPK } 1.5 \mathrm{~N}\end{array}$ & - & - & $\begin{array}{l}\text { AAN 1/5120, } \\
\text { Fluo mouchetée }\end{array}$ & $\begin{array}{l}\text { Anti-EJ douteux } \\
\text { Contrôle des anti- } \\
\text { TIF1Y négatif à } \\
\text { Rouen }\end{array}$ & $\begin{array}{l}\text { Péricardite } \\
\text { chronique } \\
\text { constrictive }\end{array}$ \\
\hline Patient 4 & $\begin{array}{l}62, \mathrm{~F} \\
\text { Anti-TIF1Y } \\
\text { positifs }\end{array}$ & $\begin{array}{l}\text { Dot myosite } \\
\text { lancé par le } \\
\text { laboratoire }\end{array}$ & Raynaud & $\begin{array}{l}0 \\
\text { CPK non dosées }\end{array}$ & $\begin{array}{l}\text { Polyneuropathie } \\
\text { axonale sensitive à } \\
\text { I'EMG } \\
\text { IRM - }\end{array}$ & - & $\begin{array}{l}\text { AAN } 1 / 1280, \\
\text { Fluo homogène + } \\
\text { cytoplasmique }\end{array}$ & $\begin{array}{l}\text { Anti-SSA, Anti-DNA } \\
\text { à } 113 \\
\text { Cryoglobuline II b } \\
10 \\
\text { LAC, ACL }\end{array}$ & $\begin{array}{l}\text { Lupus cutanéo- } \\
\text { articulaire connu } \\
\text { avec SAPL } \\
\text { secondaire }\end{array}$ \\
\hline Patient 5 & $\begin{array}{l}40, \mathrm{~F} \\
\text { Anti-TIF1X } \\
\text { positifs }\end{array}$ & $\begin{array}{l}\text { Dot myosite } \\
\text { lancé par le } \\
\text { laboratoire }\end{array}$ & 0 & $\begin{array}{l}0 \\
\text { CPK non dosées }\end{array}$ & - & - & $\begin{array}{l}\text { AAN } 1 / 2560, \\
\text { Fluo homogène + } \\
\text { cytoplasmique }\end{array}$ & $\begin{array}{l}\text { Anti-DNA à } 237 \\
\mathrm{ACL}\end{array}$ & $\begin{array}{l}\text { Lupus cutanéo- } \\
\text { articulaire connu } \\
\text { avec SAPL } \\
\text { secondaire }\end{array}$ \\
\hline Patient 6 & $\begin{array}{l}49, \mathrm{~F} \\
\text { Anti-TIF1X } \\
\text { positifs }\end{array}$ & $\begin{array}{l}\text { Myalgies avec } \\
\text { CPK } \\
\text { augmentées }\end{array}$ & 0 & $\begin{array}{l}\text { Myalgies diffuses } \\
\text { CPK } 10 \mathrm{~N}\end{array}$ & EMG et IRM N & $\begin{array}{l}\text { Pas d'arguments } \\
\text { pour une } \mathrm{MI}\end{array}$ & $\begin{array}{l}\text { AAN 1/640, } \\
\text { Fluo nucléolaire }\end{array}$ & $\begin{array}{l}\text { Anti-Hépatocytes } \\
1 / 320\end{array}$ & $\begin{array}{l}\text { Myalgies } \\
\text { inexpliquées } \\
\text { HyperCPKémie } \\
\text { essentielle }\end{array}$ \\
\hline Patient 7 & $\begin{array}{l}68, \mathrm{M} \\
\text { Anti-TIF1Y } \\
\text { positifs }\end{array}$ & $\begin{array}{l}\text { Tableau de } \\
\text { sclérodermie }\end{array}$ & $\begin{array}{l}\text { Sclérose cutanée } \\
\text { diffuse }\end{array}$ & $\begin{array}{l}0 \\
\text { CPK N }\end{array}$ & - & - & $\begin{array}{l}\text { AAN 1/5120, } \\
\text { Fluo des } \\
\text { centromères }\end{array}$ & $\begin{array}{l}\text { Anti-centromères B } \\
\text { Anti-SSA, LAC, ACL } \\
\text { Contrôle des anti- } \\
\text { TIF1Y à Rouen } \\
\text { faiblement positif }\end{array}$ & $\begin{array}{l}\text { Sclérodermie } \\
\text { systémique diffuse }\end{array}$ \\
\hline Patient 8 & $\begin{array}{l}63, \mathrm{M} \\
\text { Anti-TIF1Y } \\
\text { positifs }\end{array}$ & $\begin{array}{l}\text { Myalgies avec } \\
\text { CPK } \\
\text { augmentées }\end{array}$ & $\begin{array}{l}\text { Raynaud } \\
\text { Sclérodactylie }\end{array}$ & $\begin{array}{l}0 \\
\text { CPK 6N }\end{array}$ & $\begin{array}{l}\text { IRM normale } \\
\text { Polyneuropathie } \\
\text { axonale longueur } \\
\text { dépendante à I'EMG }\end{array}$ & - & $\begin{array}{l}\text { AAN 1/1280, } \\
\text { Fluo mouchetée }\end{array}$ & Anti-Ku & $\begin{array}{l}\text { Myosite de } \\
\text { chevauchement à } \\
\text { anti-Ku }\end{array}$ \\
\hline Patient 9 & $\begin{array}{l}\text { 71, F } \\
\text { Anti-TIF1X } \\
\text { positifs }\end{array}$ & $\begin{array}{l}\text { Tableau de } \\
\text { sclérodermie }\end{array}$ & Raynaud & $\begin{array}{l}0 \\
\text { CPK N }\end{array}$ & - & - & $\begin{array}{l}\text { AAN 1/5120, } \\
\text { Fluo des } \\
\text { centromères }\end{array}$ & $\begin{array}{l}\text { Anti-Scl70 } \\
\text { Anti-centromères B } \\
\text { Contrôle des anti- } \\
\text { TIF1Y négatif à } \\
\text { Rouen }\end{array}$ & $\begin{array}{l}\text { Sclérodermie } \\
\text { systémique limitée }\end{array}$ \\
\hline Patient 10 & $\begin{array}{l}\text { 73, M } \\
\text { Anti-TIF1X } \\
\text { positifs }\end{array}$ & $\begin{array}{l}\text { Tableau de } \\
\text { sclérodermie }\end{array}$ & $\begin{array}{l}\text { Raynaud } \\
\text { Sclérodactylie } \\
\text { Télangiectasies }\end{array}$ & $\begin{array}{l}0 \\
\text { CPK N }\end{array}$ & - & - & $\begin{array}{l}\text { AAN 1/1280, } \\
\text { Fluo des } \\
\text { centromères }\end{array}$ & $\begin{array}{l}\text { Anti-centromères B } \\
\text { Contrôle des anti- } \\
\text { TIF1Y négatif à } \\
\text { Rouen }\end{array}$ & $\begin{array}{l}\text { Sclérodermie } \\
\text { systémique limitée }\end{array}$ \\
\hline Patient 11 & $\begin{array}{l}\text { 64, M } \\
\text { Anti-TIF1Y } \\
\text { positifs }\end{array}$ & $\begin{array}{l}\text { Myalgies avec } \\
\text { CPK normales }\end{array}$ & 0 & $\begin{array}{l}\text { Myalgies proximales } \\
\text { CPK N }\end{array}$ & - & - & $\begin{array}{l}\text { AAN 1/1280, } \\
\text { Fluo finement } \\
\text { mouchetée }\end{array}$ & & $\begin{array}{l}\text { Arthromyalgies } \\
\text { inflammatoires }\end{array}$ \\
\hline Patient 12 & $\begin{array}{l}\text { 80, } \mathrm{F} \\
\text { Anti-TIF1Y } \\
\text { positifs }\end{array}$ & Non retrouvée & $\begin{array}{l}\text { Purpura } \\
\text { vasculaire }\end{array}$ & $\begin{array}{l}0 \\
\text { CPK } 1.5 \mathrm{~N}\end{array}$ & - & - & $\begin{array}{l}\text { AAN 1/1280, } \\
\text { Fluo cytoplasmique }\end{array}$ & $\begin{array}{l}\text { Cryoglobuline II } \\
\text { mixte à } 46\end{array}$ & $\begin{array}{l}\text { Poussée de } \\
\text { vascularite } \\
\text { cryoglobulinémique }\end{array}$ \\
\hline
\end{tabular}

AAN : anticorps anti-noyaux, ACL : anti-cardiolipine, EMG : électromyogramme, F : féminin, Fluo : fluorescence, FR : facteur rhumatoïde, IFI : immunofluorescence indirecte, LAC : lupus anti-coagulant, $\mathrm{M}:$ masculin, MTX : méthotrexate, PR : polyarthrite rhumatoïde, SAPL : syndrome des anti-phospholipides.

0 : signe clinique absent, - : examen non réalisé, $\mathrm{N}$ : normal 


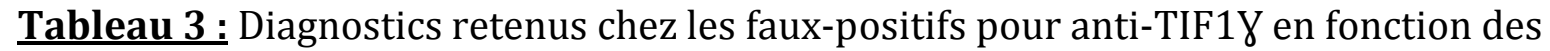
motifs de réalisation du dot myosite (patient 13 à 23)

\begin{tabular}{|c|c|c|c|c|c|c|c|c|c|}
\hline & Age, sexe & $\begin{array}{l}\text { Motif de } \\
\text { réalisation }\end{array}$ & Signes cutanés & $\begin{array}{l}\text { Signes } \\
\text { musculaires } \\
\text { CPK }\end{array}$ & $\begin{array}{l}\text { Examens réalisés } \\
\text { (EMG/IRM) }\end{array}$ & $\begin{array}{l}\text { Biopsie } \\
\text { musculaire }\end{array}$ & IFI sur HEp-2 & $\begin{array}{l}\text { Bilan } \\
\text { immunologique }\end{array}$ & $\begin{array}{l}\text { Diagnostics } \\
\text { retenus }\end{array}$ \\
\hline Patient 13 & $\begin{array}{l}\text { 65, F } \\
\text { Anti-TIF1X } \\
\text { positifs }\end{array}$ & $\begin{array}{l}\text { Pneumopathie } \\
\text { interstitielle } \\
\text { diffuse }\end{array}$ & Raynaud & $\begin{array}{l}0 \\
\text { CPK N }\end{array}$ & - & - & $\begin{array}{l}\text { AAN 1/1280, } \\
\text { Fluo finement } \\
\text { mouchetée }\end{array}$ & & $\begin{array}{l}\text { Pneumopathie } \\
\text { médicamenteuse au } \\
\text { MTX }\end{array}$ \\
\hline Patient 14 & $\begin{array}{l}37, \mathrm{~F} \\
\text { Anti-TIF1X } \\
\text { positifs }\end{array}$ & $\begin{array}{l}\text { Tableau de } \\
\text { sclérodermie }\end{array}$ & Raynaud & $\begin{array}{l}0 \\
\text { CPK N }\end{array}$ & - & - & $\begin{array}{l}\text { AAN } 1 / 2560, \\
\text { Fluo des centromères }\end{array}$ & $\begin{array}{l}\text { Anti-centromères B } \\
\text { FR à } 48\end{array}$ & $\begin{array}{l}\text { Sclérodermie } \\
\text { systémique limitée }\end{array}$ \\
\hline Patient 15 & $\begin{array}{l}75, \mathrm{~F} \\
\text { Anti-TIF1X } \\
\text { positifs }\end{array}$ & $\begin{array}{l}\text { Tableau de } \\
\text { sclérodermie }\end{array}$ & $\begin{array}{l}\text { Raynaud } \\
\text { Sclérodactylie } \\
\text { Télangiectasies }\end{array}$ & $\begin{array}{l}0 \\
\text { CPK non dosées }\end{array}$ & - & - & $\begin{array}{l}\text { AAN } 1 / 5120, \\
\text { Fluo des centromères }\end{array}$ & Anti-centromères $B$ & $\begin{array}{l}\text { Sclérodermie } \\
\text { systémique limitée }\end{array}$ \\
\hline Patient 16 & $\begin{array}{l}80, \mathrm{~F} \\
\text { Anti-TIF1X } \\
\text { douteux }\end{array}$ & Suivi de MI & 0 & $\begin{array}{l}0 \\
\text { CPK non dosées }\end{array}$ & - & - & $\begin{array}{l}\text { AAN } 1 / 320, \\
\text { Fluo mouchetée et } \\
\text { nucléolaire }\end{array}$ & $\begin{array}{l}\text { Anti-JO1 } \\
\mathrm{ACL}\end{array}$ & $\begin{array}{l}\text { Syndrome des anti- } \\
\text { synthétases à anti- } \\
\text { J01 }\end{array}$ \\
\hline Patient 17 & $\begin{array}{l}\text { 21, F } \\
\text { Anti-TIF1X } \\
\text { douteux }\end{array}$ & $\begin{array}{l}\text { Dot myosite lancé } \\
\text { par le laboratoire }\end{array}$ & 0 & $\begin{array}{l}0 \\
\text { CPK non dosées }\end{array}$ & - & - & $\begin{array}{l}\text { AAN 1/1280, } \\
\text { Fluo nucléolaire }\end{array}$ & Anti-DNA à 610 & $\begin{array}{l}\text { Pneumopathie } \\
\text { infectieuse, notion de } \\
\text { lupus articulaire }\end{array}$ \\
\hline Patient 18 & $\begin{array}{l}\text { 21, F } \\
\text { Anti-TIF1X } \\
\text { douteux }\end{array}$ & Non retrouvée & $\begin{array}{l}\text { Erythème du } \\
\text { décolleté } \\
\text { Vespertilio }\end{array}$ & $\begin{array}{l}\text { Myalgies diffuses } \\
\text { CPK N }\end{array}$ & - & - & $\begin{array}{l}\text { AAN } 1 / 320, \\
\text { Pas d'information sur } \\
\text { la fluo }\end{array}$ & $\begin{array}{l}\text { Anti-DNA à } 300 \\
\text { Anti-RNP, Anti-Sm }\end{array}$ & Poussée lupique \\
\hline Patient 19 & $\begin{array}{l}58, \mathrm{~F} \\
\text { Anti-TIF1X } \\
\text { douteux }\end{array}$ & Non retrouvée & Raynaud & $\begin{array}{l}0 \\
\text { CPK non dosées }\end{array}$ & - & - & $\begin{array}{l}\text { AAN 1/1560, } \\
\text { Fluo mouchetée gros } \\
\text { grains }\end{array}$ & $\begin{array}{l}\text { Anti-DNA à } 866 \\
\text { Anti-RNP, LAC }\end{array}$ & Poussée lupique \\
\hline Patient 20 & $\begin{array}{l}66, \mathrm{~F} \\
\text { Anti-TIF1X } \\
\text { douteux }\end{array}$ & Polyarthralgie & Raynaud & $\begin{array}{l}0 \\
\text { CPK N }\end{array}$ & $\begin{array}{l}\text { Neuropathie } \\
\text { sensitive à l'EMG } \\
\text { IRM - }\end{array}$ & - & $\begin{array}{l}\text { AAN } 1 / 2560, \\
\text { Fluo des centromères }\end{array}$ & Anti-centromères $\mathrm{B}$ & $\begin{array}{l}\text { Sclérodermie } \\
\text { systémique limitée }\end{array}$ \\
\hline Patient 21 & $\begin{array}{l}\text { 71, F } \\
\text { Anti-TIF1X } \\
\text { douteux }\end{array}$ & Non retrouvée & 0 & $\begin{array}{l}0 \\
\text { CPK non dosées }\end{array}$ & - & - & $\begin{array}{l}\text { AAN 1/640, } \\
\text { Fluo finement } \\
\text { mouchetée et } \\
\text { nucléolaire }\end{array}$ & & $\begin{array}{l}\text { Poussée de PR } \\
\text { séronégative }\end{array}$ \\
\hline Patient 22 & $\begin{array}{l}\text { 53, M } \\
\text { Anti-TIF1X } \\
\text { douteux }\end{array}$ & Suivi de MI & 0 & $\begin{array}{l}\text { Myalgies } \\
\text { proximales } \\
\text { CPK 15N }\end{array}$ & - & - & $\begin{array}{l}\text { Fluo cytoplasmique à } \\
1 / 1280\end{array}$ & $\begin{array}{l}\text { Anti-JO1 } \\
\text { Anti-SSA }\end{array}$ & $\begin{array}{l}\text { Syndrome des anti- } \\
\text { synthétases à anti- } \\
\text { J01 }\end{array}$ \\
\hline Patient 23 & $\begin{array}{l}51, \mathrm{~F} \\
\text { Anti-TIF1X } \\
\text { douteux }\end{array}$ & $\begin{array}{l}\text { Myalgies avec CPK } \\
\text { normales }\end{array}$ & 0 & $\begin{array}{l}0 \\
\text { CPK N }\end{array}$ & - & - & $\begin{array}{l}\text { AAN 1/80, } \\
\text { Fluo finement } \\
\text { mouchetée }\end{array}$ & & $\begin{array}{l}\text { Pseudo-polyarthrite } \\
\text { rhizomélique }\end{array}$ \\
\hline
\end{tabular}

AAN : anticorps anti-noyaux, ACL : anti-cardiolipine, EMG : électromyogramme, F : féminin, Fluo : fluorescence, FR : facteur rhumatoïde, IFI : immunofluorescence indirecte, LAC : lupus anti-coagulant, $\mathrm{M}$ : masculin, MTX : méthotrexate, PR : polyarthrite rhumatoïde, SAPL : syndrome des anti-phospholipides. 0 : signe clinique absent, - : examen non réalisé, $\mathrm{N}:$ normal 
Tableau 4: Diagnostics retenus chez les faux-positifs pour anti-SAE1/2 en fonction des motifs de réalisation du dot myosite

\begin{tabular}{|c|c|c|c|c|c|c|c|c|c|}
\hline & $\begin{array}{l}\text { Age, sexe, } \\
\text { Anticorps }\end{array}$ & $\begin{array}{l}\text { Motif de } \\
\text { réalisation }\end{array}$ & $\begin{array}{l}\text { Signes } \\
\text { dermatologiques }\end{array}$ & $\begin{array}{l}\text { Signes } \\
\text { musculaires } \\
\text { CPK }\end{array}$ & $\begin{array}{l}\text { Examens } \\
\text { réalisés } \\
\text { (EMG/IRM) }\end{array}$ & $\begin{array}{l}\text { Biopsie } \\
\text { musculaire }\end{array}$ & IFI sur HEp-2 & $\begin{array}{l}\text { Bilan } \\
\text { immunologique }\end{array}$ & Diagnostics retenus \\
\hline Patient 24 & $\begin{array}{l}18, \mathrm{~F} \\
\text { Anti-SAE1/2 } \\
\text { positifs }\end{array}$ & Suivi de MI & 0 & $\begin{array}{l}0 \\
\text { CPK } 1.5 \mathrm{~N}\end{array}$ & $\begin{array}{l}\text { Syndrome } \\
\text { myogène à l'EMG } \\
\text { IRM - }\end{array}$ & $\begin{array}{l}\text { Myosite } \\
\text { nécrosante }\end{array}$ & $\begin{array}{l}\text { Fluo } \\
\text { cytoplasmique } \\
\text { à } 1 / 640\end{array}$ & Anti-SRP & $\begin{array}{l}\text { Myopathie nécrosante à } \\
\text { anti-SRP }\end{array}$ \\
\hline Patient 25 & $\begin{array}{l}73, \mathrm{~F} \\
\text { Anti-SAE1/2 } \\
\text { positifs }\end{array}$ & $\begin{array}{l}\text { Pneumopathie } \\
\text { interstitielle } \\
\text { diffuse }\end{array}$ & 0 & $\begin{array}{l}0 \\
\text { CPK N }\end{array}$ & - & - & Négative & & $\begin{array}{l}\text { Pneumopathie } \\
\text { d'hypersensibilité }\end{array}$ \\
\hline Patient 26 & $\begin{array}{l}65, \mathrm{~F} \\
\text { Anti-SAE1/2 } \\
\text { positifs }\end{array}$ & $\begin{array}{l}\text { Pneumopathie } \\
\text { interstitielle } \\
\text { diffuse }\end{array}$ & Sclérodactylie & $\begin{array}{l}0 \\
\text { CPK N }\end{array}$ & - & - & Négative & & Connectivite inclassée \\
\hline Patient 27 & $\begin{array}{l}88, \mathrm{M} \\
\text { Anti-SAE1/2 } \\
\text { positifs }\end{array}$ & $\begin{array}{l}\text { Tableau de } \\
\text { sclérodermie }\end{array}$ & $\begin{array}{l}\text { Raynaud } \\
\text { Sclérodactylie } \\
\text { Ulcération pulpaire }\end{array}$ & $\begin{array}{l}0 \\
\text { CPK N }\end{array}$ & - & - & $\begin{array}{l}\text { AAN 1/160, } \\
\text { Fluo finement } \\
\text { mouchetée et } \\
\text { cytoplasmique }\end{array}$ & & $\begin{array}{l}\text { Sclérodermie systémique } \\
\text { limitée }\end{array}$ \\
\hline Patient 28 & $\begin{array}{l}65, \mathrm{~F} \\
\text { Anti-SAE1/2 } \\
\text { positifs }\end{array}$ & $\begin{array}{l}\text { Myalgies avec } \\
\text { CPK } \\
\text { augmentées }\end{array}$ & 0 & $\begin{array}{l}\text { Myalgies } \\
\text { proximales } \\
\text { CPK 4N }\end{array}$ & $\begin{array}{l}\text { Syndrome } \\
\text { myogène } \\
\text { asymétrique } \\
\text { IRM - }\end{array}$ & $\begin{array}{l}\text { Absence } \\
\text { d'arguments } \\
\text { pour une MI }\end{array}$ & $\begin{array}{l}\text { AAN 1/320, } \\
\text { Fluo } \\
\text { mouchetée }\end{array}$ & & Myalgies inexpliquées \\
\hline Patient 29 & $\begin{array}{l}59, \mathrm{~F} \\
\text { Anti-SAE1/2 } \\
\text { positifs }\end{array}$ & Non retrouvée & Panniculite (genoux) & $\begin{array}{l}0 \\
\text { CPK non } \\
\text { dosées }\end{array}$ & - & - & $\begin{array}{l}\text { AAN 1/160, } \\
\text { Fluo } \\
\text { mouchetée et } \\
\text { cytoplasmique }\end{array}$ & Anti-EJ douteux & $\begin{array}{l}\text { Panniculite d'évolution } \\
\text { spontanément favorable }\end{array}$ \\
\hline Patient 30 & $\begin{array}{l}77, \mathrm{~F} \\
\text { Anti-SAE1/2 } \\
\text { positifs }\end{array}$ & $\begin{array}{l}\text { Pneumopathie } \\
\text { interstitielle } \\
\text { diffuse }\end{array}$ & Raynaud & $\begin{array}{l}0 \\
\text { CPK N }\end{array}$ & - & - & $\begin{array}{l}\text { AAN 1/2560, } \\
\text { Fluo } \\
\text { nucléolaire } \\
\text { homogène }\end{array}$ & Anti-SSA & Syndrome de Sjogren \\
\hline Patient 31 & $\begin{array}{l}\text { 71, M } \\
\text { Anti-SAE1/2 } \\
\text { positifs }\end{array}$ & $\begin{array}{l}\text { Pneumopathie } \\
\text { interstitielle } \\
\text { diffuse }\end{array}$ & 0 & $\begin{array}{l}0 \\
\text { CPK N }\end{array}$ & $\begin{array}{l}\text { EMG N } \\
\text { IRM - }\end{array}$ & - & Négative & & $\begin{array}{l}\text { Fibrose pulmonaire } \\
\text { idiopathique }\end{array}$ \\
\hline Patient 32 & $\begin{array}{l}66, M \\
\text { Anti-SAE1/2 } \\
\text { positifs }\end{array}$ & $\begin{array}{l}\text { Pneumopathie } \\
\text { interstitielle } \\
\text { diffuse }\end{array}$ & 0 & $\begin{array}{l}0 \\
\text { CPK } 1.5 \mathrm{~N}\end{array}$ & EMG N & - & $\begin{array}{l}\text { AAN 1/640, } \\
\text { Fluo } \\
\text { mouchetée et } \\
\text { cytoplasmique }\end{array}$ & Anti-PL12 & $\begin{array}{l}\text { Pneumopathie } \\
\text { d'hypersensibilité }\end{array}$ \\
\hline Patient 33 & $\begin{array}{l}63, \mathrm{~F} \\
\text { Anti-SAE1/2 } \\
\text { positifs }\end{array}$ & $\begin{array}{l}\text { Dot myosite } \\
\text { lancé par le } \\
\text { laboratoire }\end{array}$ & 0 & $\begin{array}{l}0 \\
\text { CPK non } \\
\text { dosées }\end{array}$ & - & - & $\begin{array}{l}\text { AAN 1/5120, } \\
\text { Fluo des } \\
\text { nuclear dot et } \\
\text { cytoplasmique }\end{array}$ & Anti-M2 & $?$ \\
\hline $\begin{array}{l}\text { Patient } \\
34\end{array}$ & $\begin{array}{l}87, \mathrm{M} \\
\text { Anti-SAE1/2 } \\
\text { douteux }\end{array}$ & $\begin{array}{l}\text { Pneumopathie } \\
\text { interstitielle } \\
\text { diffuse }\end{array}$ & 0 & $\begin{array}{l}0 \\
\text { CPK N }\end{array}$ & - & - & Négative & & $\begin{array}{l}\text { Fibrose pulmonaire } \\
\text { idiopathique }\end{array}$ \\
\hline Patient 35 & $\begin{array}{l}55, \mathrm{~F} \\
\text { Anti-SAE1/2 } \\
\text { douteux }\end{array}$ & Non retrouvée & 0 & $\begin{array}{l}0 \\
\text { CPK N }\end{array}$ & $\begin{array}{l}\text { Polyneuropathie } \\
\text { axonale sensitive } \\
\text { à l'EMG } \\
\text { IRM - }\end{array}$ & $\begin{array}{l}\text { Atteinte } \\
\text { axonale } \\
\text { chronique }\end{array}$ & $\begin{array}{l}\text { AAN 1/320, } \\
\text { Fluo finement } \\
\text { mouchetée }\end{array}$ & Anti-DNA & $\begin{array}{l}\text { Polyneuropathie axonale } \\
\text { sensitive }\end{array}$ \\
\hline Patient 36 & $\begin{array}{l}66, \mathrm{M} \\
\text { Anti-SAE1/2 } \\
\text { douteux }\end{array}$ & $\begin{array}{l}\text { Tableau } \\
\text { évocateur de } \\
\text { DM }\end{array}$ & $\begin{array}{l}\text { Erythrodermie } \\
\text { Purpura } \\
\text { Enanthème }\end{array}$ & $\begin{array}{l}0 \\
\text { CPK N }\end{array}$ & $\begin{array}{l}\text { Multinévrite à } \\
\text { I'EMG } \\
\text { IRM - }\end{array}$ & $\begin{array}{l}\text { Atteinte } \\
\text { axonale } \\
\text { subaigüe }\end{array}$ & $\begin{array}{l}\text { Fluo } \\
\text { cytoplasmique }\end{array}$ & aANCA $1 / 640$ & Sarcoïdose systémique \\
\hline Patient 37 & $\begin{array}{l}57, \mathrm{M} \\
\text { Anti-SAE1/2 } \\
\text { douteux }\end{array}$ & $\begin{array}{l}\text { Myalgies avec } \\
\text { CPK normales }\end{array}$ & 0 & $\begin{array}{l}\text { Myalgies para- } \\
\text { vertébrales }\end{array}$ & - & - & $\begin{array}{l}\text { AAN 1/80 } \\
\text { Fluo } \\
\text { mouchetée }\end{array}$ & & Myalgies inexpliquées \\
\hline Patient 38 & $\begin{array}{l}61, \mathrm{M} \\
\text { Anti-SAE1/2 } \\
\text { douteux }\end{array}$ & $\begin{array}{l}\text { Myalgies avec } \\
\text { CPK } \\
\text { augmentées }\end{array}$ & 0 & $\begin{array}{l}\text { Myalgies } \\
\text { proximales } \\
\text { CPK } 5 \mathrm{~N}\end{array}$ & $\begin{array}{l}\text { IRM musculaire } \mathrm{N} \\
\text { EMG - }\end{array}$ & Normale & $\begin{array}{l}\text { AAN 1/80 } \\
\text { Fluo } \\
\text { mouchetée }\end{array}$ & & $\begin{array}{l}\text { Myalgies inexpliquées } \\
\text { HyperCPKémie essentielle }\end{array}$ \\
\hline
\end{tabular}

AAN : anticorps anti-noyaux, DM : dermatomyosite, EMG : électromyogramme, F : féminin, Fluo : fluorescence, FR : facteur rhumatoïde, IFI :

immunofluorescence indirecte, $\mathrm{M}$ : masculin, $\mathrm{MI}$ : myopathie inflammatoire, MTX : méthotrexate

0 : signe clinique absent, - : examen non réalisé, $\mathrm{N}$ : normal 
Tableau 5: Diagnostics retenus chez les faux-positifs pour anti-NXP2 en fonction des motifs de réalisation du dot myosite

\begin{tabular}{|c|c|c|c|c|c|c|c|c|c|}
\hline & $\begin{array}{l}\text { Age, sexe, } \\
\text { Anticorps }\end{array}$ & $\begin{array}{l}\text { Motif de } \\
\text { réalisation }\end{array}$ & $\begin{array}{l}\text { Signes } \\
\text { cutanés }\end{array}$ & $\begin{array}{l}\text { Signes } \\
\text { musculaires }\end{array}$ & $\begin{array}{l}\text { Examens } \\
\text { réalisés } \\
\text { (EMG/IRM) }\end{array}$ & $\begin{array}{l}\text { Biopsie } \\
\text { musculaire }\end{array}$ & IFI sur HEp-2 & $\begin{array}{l}\text { Bilan } \\
\text { immunologique }\end{array}$ & Diagnostics retenus \\
\hline Patient 39 & $\begin{array}{l}18, \mathrm{~F} \\
\text { Anti-NXP2 } \\
\text { douteux }\end{array}$ & Suivi de MI & 0 & $\begin{array}{l}0 \\
\text { CPK } 1.5 \mathrm{~N}\end{array}$ & $\begin{array}{l}\text { Syndrome } \\
\text { myogène à } \\
\text { I'EMG } \\
\text { IRM - }\end{array}$ & $\begin{array}{l}\text { Myopathie } \\
\text { nécrosante }\end{array}$ & $\begin{array}{l}\text { Fluo } \\
\text { cytoplasmique à } \\
1 / 640\end{array}$ & Anti-SRP & Myopathie nécrosante à anti-SRP \\
\hline Patient 40 & $\begin{array}{l}34, \mathrm{M} \\
\text { Anti-NXP2 } \\
\text { positifs }\end{array}$ & Suivi de MI & 0 & $\begin{array}{l}0 \\
\text { CPK N }\end{array}$ & - & - & $\begin{array}{l}\text { AAN 1/640, } \\
\text { Fluo mouchetée }\end{array}$ & Anti-Ku & Myosite à anti-Ku \\
\hline Patient 41 & $\begin{array}{l}48, \mathrm{~F} \\
\text { Anti-NXP2 } \\
\text { positifs }\end{array}$ & $\begin{array}{l}\text { Myalgies avec } \\
\text { CPK augmentées }\end{array}$ & $\begin{array}{l}\text { Télangiectasies, } \\
\text { œdème péri- } \\
\text { unguéal }\end{array}$ & $\begin{array}{l}\text { Myalgies } \\
\text { proximales }\end{array}$ & $\mathrm{N}$ & - & AAN $1 / 640$ & Anti-centromères $B$ & $\begin{array}{l}\text { Sclérodermie systémique limitée } \\
\text { sans myosite } \\
\text { Myalgies inexpliquées }\end{array}$ \\
\hline Patient 42 & $\begin{array}{l}63, \mathrm{~F} \\
\text { Anti-NXP2 } \\
\text { positifs }\end{array}$ & $\begin{array}{l}\text { Tableau de } \\
\text { sclérodermie }\end{array}$ & Raynaud récent & $\begin{array}{l}0 \\
\text { CPK N }\end{array}$ & $\mathrm{N}$ & Normale & $\begin{array}{l}\text { AAN 1/2560, } \\
\text { Fluo des } \\
\text { centromères }\end{array}$ & Anti-centromères $B$ & Sclérodermie systémique limitée \\
\hline Patient 43 & $\begin{array}{l}\text { 44, } \mathrm{F} \\
\text { Anti-NXP2 } \\
\text { positifs }\end{array}$ & $\begin{array}{l}\text { Dot myosite } \\
\text { lancé par le } \\
\text { laboratoire }\end{array}$ & 0 & $\begin{array}{l}0 \\
\text { CPK N }\end{array}$ & - & - & $\begin{array}{l}\text { Fluo } \\
\text { cytoplasmique }\end{array}$ & & Maladie de Takayashu quiescente \\
\hline Patient 44 & $\begin{array}{l}83, \mathrm{~F} \\
\text { Anti-NXP2 } \\
\text { douteux }\end{array}$ & $\begin{array}{l}\text { Tableau de } \\
\text { sclérodermie }\end{array}$ & $\begin{array}{l}\text { Raynaud } \\
\text { Sclérodactylie, } \\
\text { Télangiectasies, } \\
\text { Calcinose }\end{array}$ & $\begin{array}{l}0 \\
\text { CPK N }\end{array}$ & - & - & $\begin{array}{l}\text { AAN } 1 / 2560, \\
\text { Fluo finement } \\
\text { mouchetée }\end{array}$ & $\begin{array}{l}\text { Anti-SSA } \\
\text { FR à } 43\end{array}$ & Sclérodermie systémique limitée \\
\hline Patient 45 & $\begin{array}{l}\text { 35, M } \\
\text { Anti-NXP2 } \\
\text { douteux }\end{array}$ & $\begin{array}{l}\text { Myalgies avec } \\
\text { CPK augmentées }\end{array}$ & 0 & $\begin{array}{l}\text { Myalgies } \\
\text { proximales } \\
\text { CPK } 1.5 \mathrm{~N}\end{array}$ & $\begin{array}{l}\text { Multinévrite } \\
\text { à I'EMG } \\
\text { IRM - }\end{array}$ & $\begin{array}{l}\text { Vascularite } \\
\text { nécrosante }\end{array}$ & $\begin{array}{l}\text { Fluo } \\
\text { cytoplasmique }\end{array}$ & & Péri-Artérite noueuse \\
\hline Patient 46 & $\begin{array}{l}\text { 73, M } \\
\text { Anti-NXP2 } \\
\text { douteux }\end{array}$ & $\begin{array}{l}\text { Pneumopathie } \\
\text { interstitielle } \\
\text { diffuse }\end{array}$ & 0 & $\begin{array}{l}\text { Myalgies } \\
\text { proximales } \\
\text { CPK N }\end{array}$ & - & - & $\begin{array}{l}\text { AAN 1/160, } \\
\text { Fluo mouchetée }\end{array}$ & & $\begin{array}{l}\text { Pseudo-polyarthrite rhizomélique } \\
\text { connue } \\
\text { Suspicion de PNP au MTX }\end{array}$ \\
\hline Patient 47 & $\begin{array}{l}35, \mathrm{~F} \\
\text { Anti-NXP2 } \\
\text { douteux }\end{array}$ & $\begin{array}{l}\text { Myalgies avec } \\
\text { CPK normales }\end{array}$ & 0 & $\begin{array}{l}\text { Myalgies } \\
\text { proximales } \\
\text { CPK N }\end{array}$ & $\mathrm{N}$ & Normale & AAN $1 / 80$ & & Myalgies inexpliquées \\
\hline Patient 48 & $\begin{array}{l}\text { 63, M } \\
\text { Anti-NXP2 } \\
\text { douteux }\end{array}$ & $\begin{array}{l}\text { Pneumopathie } \\
\text { interstitielle } \\
\text { diffuse }\end{array}$ & 0 & $\begin{array}{l}\text { Myalgies } \\
\text { proximales } \\
\mathrm{CPKN}\end{array}$ & - & - & AAN $1 / 80$ & & Fibrose pulmonaire idiopathique \\
\hline
\end{tabular}

AAN : anticorps anti-noyaux, F : féminin, Fluo : fluorescence, FR : facteur rhumatoïde, IFI : immunofluorescence indirecte, $\mathrm{M}:$ masculin, MI : myopathie inflammatoire, MTX :

méthotrexate, PNP : pneumopathie

0 : signe clinique absent, - : examen non réalisé, $\mathrm{N}$ : normal 